\title{
Development, structure and function of the cranial suspensory ligaments of the mammalian gonads in a cross-species perspective; their possible role in effecting disturbed testicular descent
}

\author{
Pieter van der Schoot ${ }^{1}$ and Judith M.A.Emmen
}

Department of Endocrinology \& Reproduction, Erasmus University Rotterdam, Faculty of Medicine and Health Sciences, PO Box 1738, 3000 DR Rotterdam, The Netherlands

\section{TABLE OF CONTENTS}

Introduction

The nature of the cranial suspensory ligaments of the gonads and the genital ducts

Sexual dimorphism in the further development of the mammalian CSL

Species differences in extent of CSL development in female mammals

Exceptions to a rule: marked CSL development in male mammals with testis descent

Further exceptions to the rule: development of the CSL in species with testicondia

Hormonal control of suppressed development of the CSL in males

Development and persistence of the CSL as a potential key factor in the aetiology of cryptorchidism

Human male and female development of the CSL

Concluding remarks

Acknowledgements

References

The present review aims to present a perspective on a relatively unknown part of the mammalian internal genitalia: their cranial suspensory apparatus. This apparatus shows wide divergence of development when examined during the fetal period or during adulthood, in males or females, or in individuals across a variety of species. In rats and other mammalian species the apparatus undergoes a distinct pattern of sexually dimorphic development and fetal testicular androgens are proposed to play a key role in this process. Extensive development of this suspensory apparatus in females is argued to be a part of the anatomical adaptations of the genital apparatus to support the internal genitalia throughout pregnancy, including the relatively enormous growth towards the time of parturition. Minor development of this apparatus in males is judged to be a part of the anatomical requirements allowing developing testes to become displaced from the dorsal abdominal wall during the first stage of testicular descent. Extensive development of this suspensory apparatus in males generally seems to hinder testicular descent. Accordingly, the apparatus is well developed in so-called testicond species which do not show testis descent as a part of their normal male genital development. Furthermore, arguments are adduced that inappropriate and extensive development in species with testis descent may be a key aetiological factor in the disturbance of this process. Diagnosis and treatment of human cryptorchidism might profit from including an analysis of the development and function of (remnants of) the cranial testicular and epididymal suspensory apparatus.

Key words: cranial suspensory apparatus/ cryptorchidism/genital development/testicular descent

\section{Introduction}

The study of mammalian gonadal and genital differentiation has been a popular choice ever since the epoch-making discoveries by the late Alfred Jost in Paris during the 1940s (reviewed in Jost, 1953). Directly and indirectly, these investigations have contributed importantly to the development of valid and detailed models of hormone action on

${ }^{1}$ To whom correspondence should be addressed. Phone: 3110408 7591; Fax: 3110436 6832; E-mail address: vanderschoot@endov.fgg.eur.nl. 
gonadal and genital development. Furthermore, they have been the base upon which detailed models for understanding hormone actions at the general somatic/organic level have been built, both prior to and including their molecular details (Wilson et al., 1981, 1995; Josso et al., 1993). Jost's investigations revealed the way by which the initially bipotential primordia of the various components of the genital system develop into either a male- or a female-typed differentiated series of structures under the influence of chromosomal (the gonads) or gonadal hormonal factors (the genital ducts, accessory glands and external genitalia). Throughout these studies, the whole of the investigative effort was directed towards the analysis of gonadal growth and differentiation (ovaries and testes), the differentiation of the epithelia and immediately surrounding stroma of the genital ducts (Wolffian and Müllerian ducts and their derivatives), and towards the external genitalia. Almost no attention has been paid to the analysis of the other parts of the developing internal genitalia, including, specifically, the genital mesenteries and their associated structures. The latter also show obvious sexually dimorphic patterns of growth and development but these have not attracted specific attention. Not unexpectedly, then, the determinants of their growth have either been considered as following 'simply' or 'passively' the sexually dimorphic growth of the gonads and genital ducts or not considered worth the effort of any specific analysis at all.

Two parts of these latter structures have been determined during recent investigations to show a definable pattern of development which cannot be correlated 'simply' with the remaining genitalia. These structures are the gubernaculum, which develops below the caudal pole of the genitalia in the inguinal area of the abdominal cavity, and the cranial suspensory ligaments (CSL), which develop between the dorsal abdominal wall and the cranial tip of the gonad plus the attached genital duct.

The gubernaculum has a long history of controversy: despite more than 200 years of extensive investigations, its nature (anatomy) and the control of its growth in male and female individuals have remained unclear (van der Schoot, 1996c). It now appears more and more likely, however, that gubernacular growth follows a defined male or female pattern and that the male pattern is effected through a fetal testicular hormone. The latter substance is different from testosterone (or androgens) and anti-Müllerian hormone, the two fetal testicular hormones effecting male internal and external genitalia development that are already known (Behringer et al., 1994; van der Schoot et al., 1995).

The CSL has hardly profited at all from the wealth of investigative interest in genital morphogenesis since the 1940s. However, during recent investigations with rats, data were obtained which indicated a specific significance of these structures for inducing cryptorchidism in experimentally modified male animals (van der Schoot and Elger, 1992). A search through data in the literature and analysis of various other mammalian species then suggested that the CSL could play a role in failure of testis descent in more animal species. It seemed as if the CSL had not received the attention that it should have to understand properly its contribution during normal and aberrant development of the male and female internal genitalia.

The aim of this review therefore was to collect the presently available data on the CSL during normal mammalian genital development including, specifically, the difference in development between males and females and between males in species with or without testis descent. Based on these data, a hypothesis is proposed to consider aberrant growth of the CSL as a potentially important aetiological factor in cryptorchidism among animals and in humans.

\section{The nature of the cranial suspensory ligaments of the gonads and the genital ducts}

Gonads in mammals develop initially as part of the ventromedial surface of the mesonephroi or fetal kidneys (Figure 1). These organs, in turn, make up the larger part of the longitudinal strands (urogenital ridges) of tissues developing from the fetal intermediary somatic mesoderm along both sides of the midline of the dorsal abdominal wall of the fetus (Hinrichsen, 1990). The cranial end of each mesonephros is adjacent to the last segment of the ipsilateral pronephros, and this organ generally does not reach a stage of significant size or functional activity in mammals (Romer, 1949; Grinsted and Aagesen, 1984). Its cranial end thus also reaches the level of the future diaphragm. Caudal to the mesonephric body, the free lower part of the mesonephric, or Wolffian, duct runs between the caudolateral border of the mesonephros and the urogenital sinus. The latter structure, in turn, develops as a single organ extending on both sides of the body midline. Initially, the mesonephros and its attached duct develop as retroperitoneal structures and they are thus covered on their ventral aspect with a layer of peritoneum. During further development, however, they become elevated from the dorsal body wall and develop accordingly as intraperitoneal organs. Dorsally, the peritoneal coverings from the lateral and medial mesonephric aspect become united into a mesentery sheet between the dorsal surface of the mesonephros and the mesonephric duct at one end and the abdominal wall at the other end. Cranially, the peritoneal coverings of the cranial tip of the mesonephros fuse with the peritoneum covering the further dorsal wall of the abdominal cavity. 

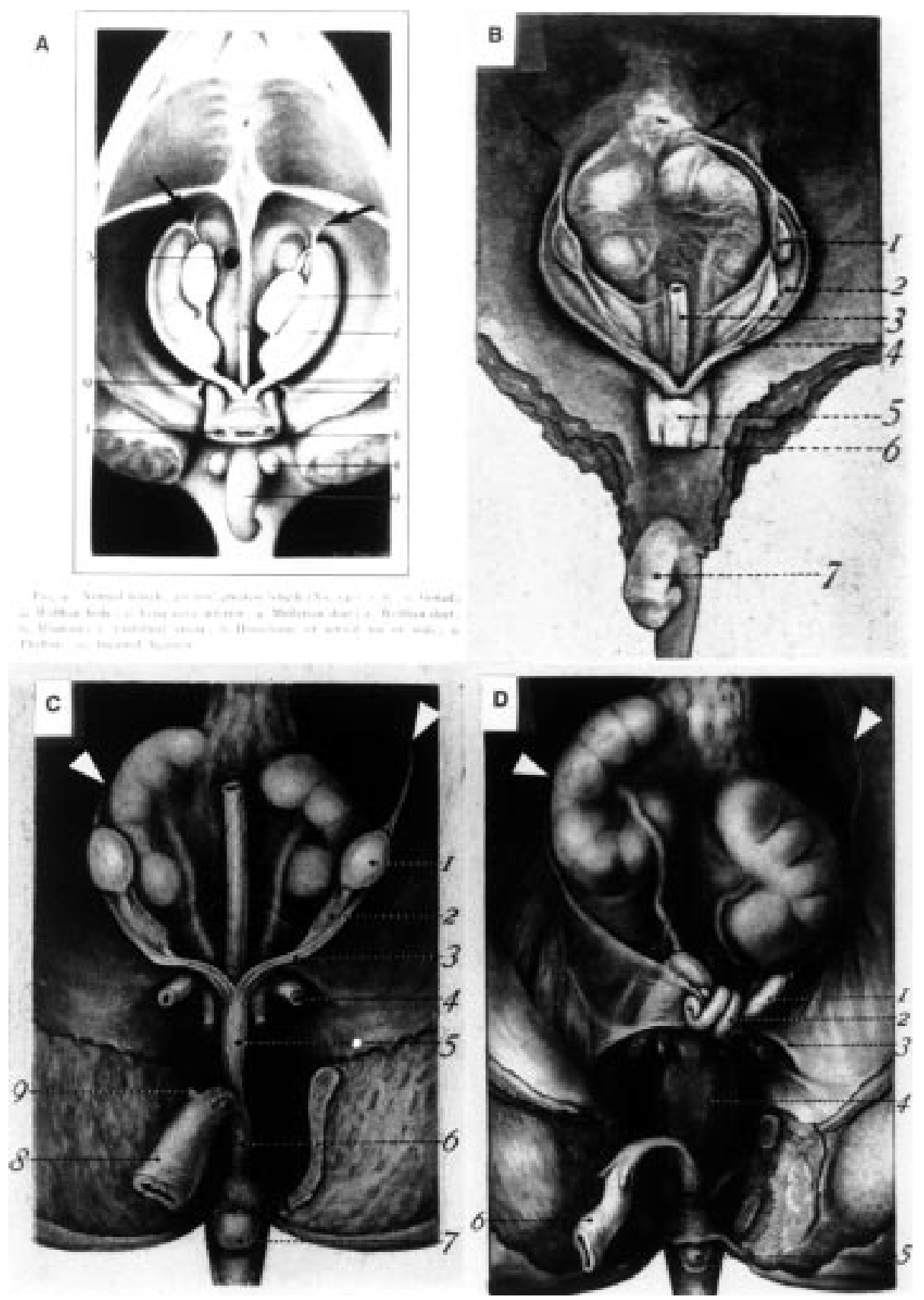

Figure 1. (A-D) Development of the cranial suspensory ligaments (CSL) in bovine fetuses. Pictures are reproduced from Lillie (1917, 1923) with permission of the publishers. Numbers and letters are copied from the original figures and do not indicate, accordingly, identical structures in the four pictures; not all numbers are explained in all figures in this legend. The $3.6 \mathrm{~cm}$ female fetus (inA) shows the large size of the mesonephros (2) and the ovary (1) developing on its ventral aspect. At the cranial tip the CSL (solid arrows) inserts immediately lateral to the adrenal glands. InB, the enlarged metanephros ascends and the cranial parts of the mesonephros (2) and associated gonad (1) become displaced in a lateral direction and this process continues during further development (in $\mathbf{C}$ and $\mathbf{D}$ ). In $\mathbf{B}$ the tip of the CSL (arrows) is still close to the midline. The location of the tip of the left CSL in $\mathbf{C}$ and $\mathbf{D}$ (white arrowheads) suggests that the lateral displacement of the CSL does not result only from displacement through the metanephros, as it is attached to the dorsal abdominal wall at a site far more lateral than the lateral border of the metanephros.

However, there may develop or persist a more or less conspicuous strand of tissues ('ligament') between the mesonephric tip and a site in the craniolateral surface of the dorsal abdominal wall. This strand contains, initially, the blood vessels, nerves and other structures which had devel- oped earlier between the cranial part of the mesonephros and the dorsal abdominal wall. The peritoneal epithelium covering this ligament fuses with the further peritoneal covering of the abdominal wall at this site of insertion. The site of insertion is generally in the region where the develop- 
ing diaphragm becomes attached to the dorsal abdominal wall (the area of the future diaphragmatic crura and lowest ribs).

The gonads emerge from the ventromedial mesonephric surface. Initially, they develop as a part of this surface and, thus, their peritoneal covering is confluent with that of the remaining mesonephros. Soon, however, the gonad becomes elevated from the mesonephric surface, except for its cranial end (see Figures 1 and 2). A gonadal mesentery then emerges between the middle and caudal part of the gonad and the ventral mesonephric surface and this mesentery persists as the mesovary or mesorchium during later life in females and males respectively. Between the cranial part of the gonad and the mesonephric surface the gonadal peritoneal covering develops in a ligament-like fashion: herewith, the cranial part of the gonad becomes connected with the above-mentioned ligament-like strand extending from the cranial end of the mesonephros. After mesonephric regression, the gonadal cranial ligament and its covering peritoneal epithelium become united with the ligament between the mesonephric tip and the dorsal abdominal wall. Through these united ligaments the developing gonads receive a cranial part of their vasculature and innervation.

Regression of the mesonephric bodies leaves the gonads and the further internal genitalia (the Müllerian and Wolffian duct derivatives) as intraperitoneal organs connected to the dorsal body wall through distinct mesenteries: the gonadal mesentery runs between the gonad and the mesonephric duct in males, or the paramesonephric duct in females; the genital duct mesentery develops into the uterine broad ligament and mesosalpinx in females, and the mesentery of the epididymis and deferent duct in males; the cranial end of the genital mesentery contains, as its cranial border, the structure which remains from the earlier cranial gonadal and mesonephric ligament. The latter structure is to be considered the earliest stage of development of the gonadal CSL properly (van der Schoot, 1993b).

Figure 2. (A-E) Transverse sections through the degenerating mesonephros ( $\mathrm{M}$ in $\mathbf{C}$ ) and through the ovary (OV in $\mathbf{B})$ of a 60 day old bovine fetus. Its cranial tip (CSL in A) shows no recognizable mesonephric elements but clearly recognizable vascular elements. Further below (in B), there are no vascular connections between the mesonephric remnants and the dorsal abdominal wall. The major ovarian vessels (curved arrow in $\mathbf{C}$ ) pass through the still structurally intact upper part of the mesonephros (M) and, via the subperitoneal layers of the dorsal abdominal wall, to the body midline, thereby passing ventral to the ureter (indicated by UR in C). Further below (in $\mathbf{D}$ and $\mathbf{E}$ ), some vascular remnants (solid arrows) remain between the mesonephric corpuscles and the nearby abdominal wall and (in E) between the wall and the mesonephric ducts.
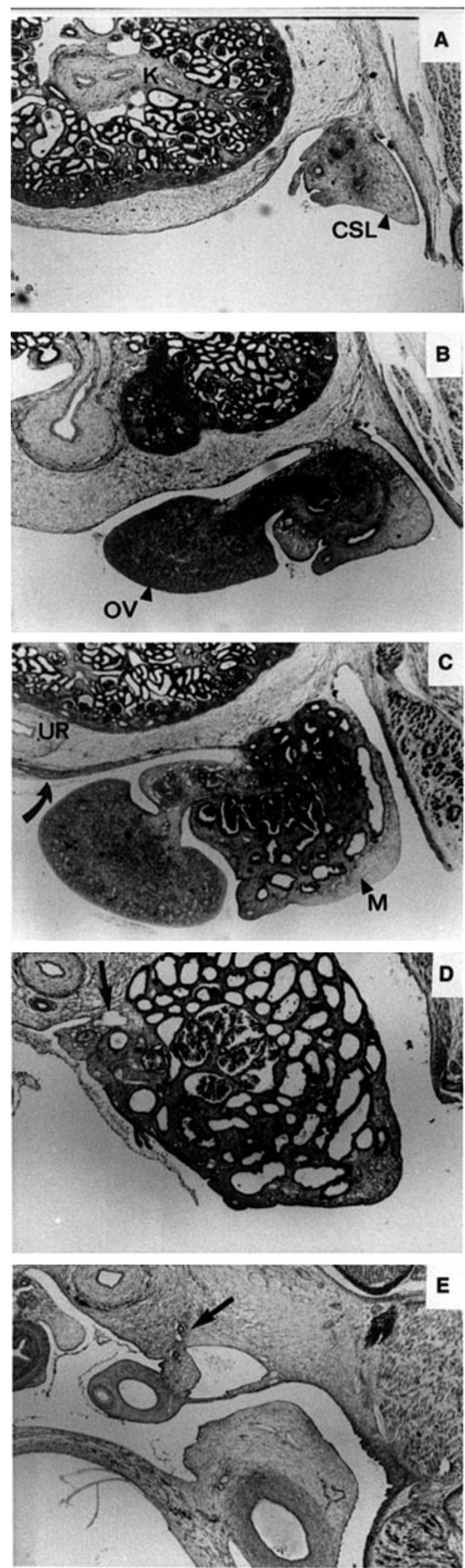
During the initial stages of its development, the CSL runs close to the midline from the cranial tip of the genital ridge in the cranial direction. It may appear to become confluent, at its cranial end, with the peritoneal covering of the ipsilateral adrenal gland (Figure 1A). Soon, however, its structure and position change due to ascent of the metanephros (the true or definitive kidney). In mammals, this organ acquires a further cranial position unlike that in other vertebrates (Romer, 1949). It achieves its ascent through a 'sheet' of loose mesenchyme lying just ventral to the developing axial musculature. During ascent the kidney increases rapidly in size and tends, therefore, to displace the genital ridge derivatives in a lateral direction (Sonneland, 1925). Figure 1 illustrates this latter process in developing bovine fetuses. During an early stage of development (3.75-7.5 cm body length in Figure 1A and B; estimated postconceptional age approximately 50 and 62 days respectively, according to Jost et al., 1972) kidneys become clearly distinguishable. At the level of the middle of these organs the gonads and associated mesonephric remnants become displaced from the original midline position. Their cranial end has not yet advanced to such level as to displace the site of insertion of the CSL. At a further advanced stage of development (Figure 1C; $10 \mathrm{~cm}$ body length; approximately 70 days after conception), ascent of the cranial tip of the kidney has resulted in marked lateral displacement of the CSL tips. Thus, growth and development of the kidneys might be the key determinant of the generally occurring $\mathrm{V}$-shape of the mammalian female internal genitalia.

During the process of displacement in the lateral direction, conspicuous alterations occur in the vascular connections of the mesonephros, and thus also of the gonads associated with them. Initially, vascular connections are rather homogeneously distributed along the whole length of the mesonephric body (Hinrichsen, 1990; Van der Schoot, 1996a). Upon ascent of the enlarging metanephros, and possibly associated with the onset of mesonephric regression at its cranial part, the homogeneous cranial part of the vascular apparatus becomes divided into two distinct components: the minor cranial part remains associated with the further developing cranial ligament of the gonadal and mesonephric mesentery; the major part becomes a conspicuous vascular stem collecting all vessels from the medial and caudal part of the mesonephric body, thus shaping the major gonadal and genital vasculature (the future ovarian/uterine vascular stem in females and pampiniform plexus in males). This latter stem runs almost horizontally below the peritoneal cover of the dorsal abdominal wall between the gonad and the body midline, thereby passing below the caudal pole of the kidney and ventral to the ipsilateral ureter. The gonadal vascular stem emerges from the cranial pole of the developing gonad (Figure 2). Further caudally, the remaining vasculature of the free mesonephric and para-mesonephric duct develops into that of the cervical part of the uterus and of the vagina, or of the epididymal cauda and deferent duct in females and males respectively.

During ascent and the concomitant increase in size of the metanephros, the mesonephric/genital mesentery (specifically: the broad ligament) becomes partially confluent with the emerging and further developing kidney capsule. The enlarging and ascending metanephros pushes the genitalia aside and lateral genital displacement, as a result of this process, goes further as more cranial parts of the genitalia become involved. During the same period, testes in many animal species tend to occupy low positions in the abdomen whereas ovaries ascend together with the ascending kidneys (van der Schoot, 1993a; Shono et al., 1995).

Lateral displacement of the cranial part of the developing genitalia does not seem to be completely explainable as part of the sequelae of ascent of the developing metanephros. As can be seen in Figures 1 and 3, the developing gonads may reach a position well away from the lateral border of the metanephros. The possibility must be considered that lateral displacement of the cranial part of the genitalia also follows an intrinsic growth process of the cranial part of the internal genitalia and their mesenteries in a lateral direction, together with part of the developing dorsal abdominal wall into which insertion of the cranial tip of the mesonephric (genital) mesentery has taken place.

\section{Sexual dimorphism in the further development of the mammalian CSL}

The CSL, as defined above, is thus a part of the normal anatomy not only of the developing mammalian genital system but in fact of all vertebrate species (Romer, 1949). It serves to suspend the cranial tip of the developing gonads and attached genital duct to the cranial part of the dorsal abdominal wall. As such it has a clear function, and accordingly structure, throughout the submammalian vertebrate species. One might expect that the typically mammalian feature of intra-uterine initial development after fertilization adds new and specific requirements, and hence anatomical differentiation, to structures involved collectively in the suspension of the internal genitalia apparatus on the dorsal abdominal wall.

In females of most mammalian species, the CSL is indeed an easily distinguishable structure which has a clear function to suspend the cranial part of the genitalia (the ovary and the adjacent tip of the oviduct) at the craniolateral tip of the dorsal abdominal wall. The ovaries often develop in close association with the caudal pole of the 

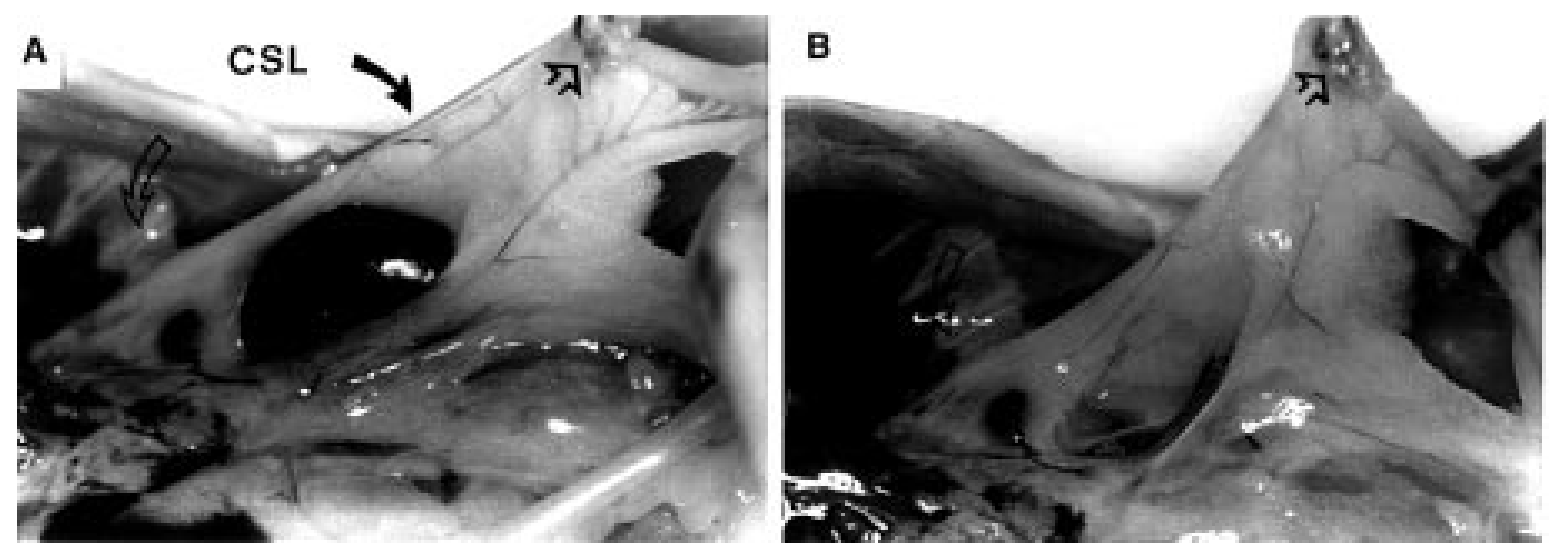

Figure 3. The ventral aspect of the left genital apparatus of an adult female rat before (A) and after (B) excision of the metanephros. The ovary (arrowhead) is pulled with forceps, revealing the mesentery (filled with fatty tissue) between the ovary and the dorsal abdominal wall with a marked cranial suspensory ligament (CSL, indicated by curved solid arrow in A) as its outer border. The CSL inserts in the area of the lowest ribs (open arrows). After removal of the kidney, it can be noticed that the site of insertion of the CSL is well lateral to the lateral border of the kidney.

kidneys: the CSL runs, accordingly, between the gonads and the dorsal abdominal wall in the area of the lowest ribs and crosses thereby the area dorsolateral to the kidney. During adulthood, the CSL in females may contain specific vasculature and innervation; it has been proposed that the major part of the ovarian adrenaline supply in rats depends on an intact innervation via the CSL (Lawrence and Burden, 1980). In guinea pigs, the CSL is so conspicuously provided with smooth muscle cells that the structure has been described as the costo-uterine muscle: the smooth muscle fibres of the CSL have their origin in the tissues ventral to the lowest ribs and merge, caudally, with the muscles of the uterine wall beyond the tubo-uterine junction (Figure 4; Melton and Saldivar, 1970; Gabella, 1976; Nickel et al., 1987).

The proposed significance of the fully developed female CSL in providing the necessary support for the internal genitalia, especially towards the end of pregnancy (the time of the maximum uterine size and weight), has not received immediate experimental proof in rats. Destruction of CSL during prepubertal life (day 20 after birth) or during adulthood (3 months) appeared to have no effect on ovarian cycles, numbers of ovulations per cycle, pregnancy, parturition or postpartum lactational pseudopregnancy (Roche $e t$ al., 1985; Wylie et al., 1985; van der Schoot, unpublished observations). Therefore, the biological significance of their strong development is still in need of further clarification.

In males of most mammalian species, the testes and mesonephric remnants leave the position of their initial emergence as a part of the genital ridge. Via an as yet poorly understood process of so-called testicular descent, they reach the lumen and, with their caudal part, almost the bottom of the caudally directed hernia sac-like extensions of the abdominal lumen in the inguinal area. The passage of the testes through the lower abdominal lumen and into these hernia sac-like processus vaginales is facilitated through the stunted development of the male CSL (van der Schoot, 1993a). Until recently, however, not much attention had been paid to this potentially important contribution of stunted CSL development to the process of testis descent. At least implicitly, on most occasions, absence of development of the CSL was judged a process 'passively following' the male-specific strong development of the gubernaculum and the associated primordia of the processus vaginalis at the caudal side of the genitalia. These implicit assumptions disregarded completely the nature of the female- and male-specific development of the CSL, including its specific innervation and vascularization in females as described above. The data discussed above make it difficult to accept failure of its emergence as a significant structure during male development to be merely the consequence of strong development of caudally situated genital ligaments: male-specific genital development requires regression and/or active inhibition of the growth of structures which attain considerable extension, differentiation and functional activity in females (van der Schoot et al., 1995; Kersten et al., 1996).

\section{Species differences in extent of CSL development in female mammals}

Earlier reports considered the size, muscularity and specific innervation of the CSL in guinea pigs and rats (Melton and Saldivar, 1970; Gabella, 1976; Guglielmone and Vercelli, 1991). As shown in Figure 4, guinea pigs indeed possess a considerable muscular strand between the tip of the ovary and the abdominal wall lateral to the kidneys. In 

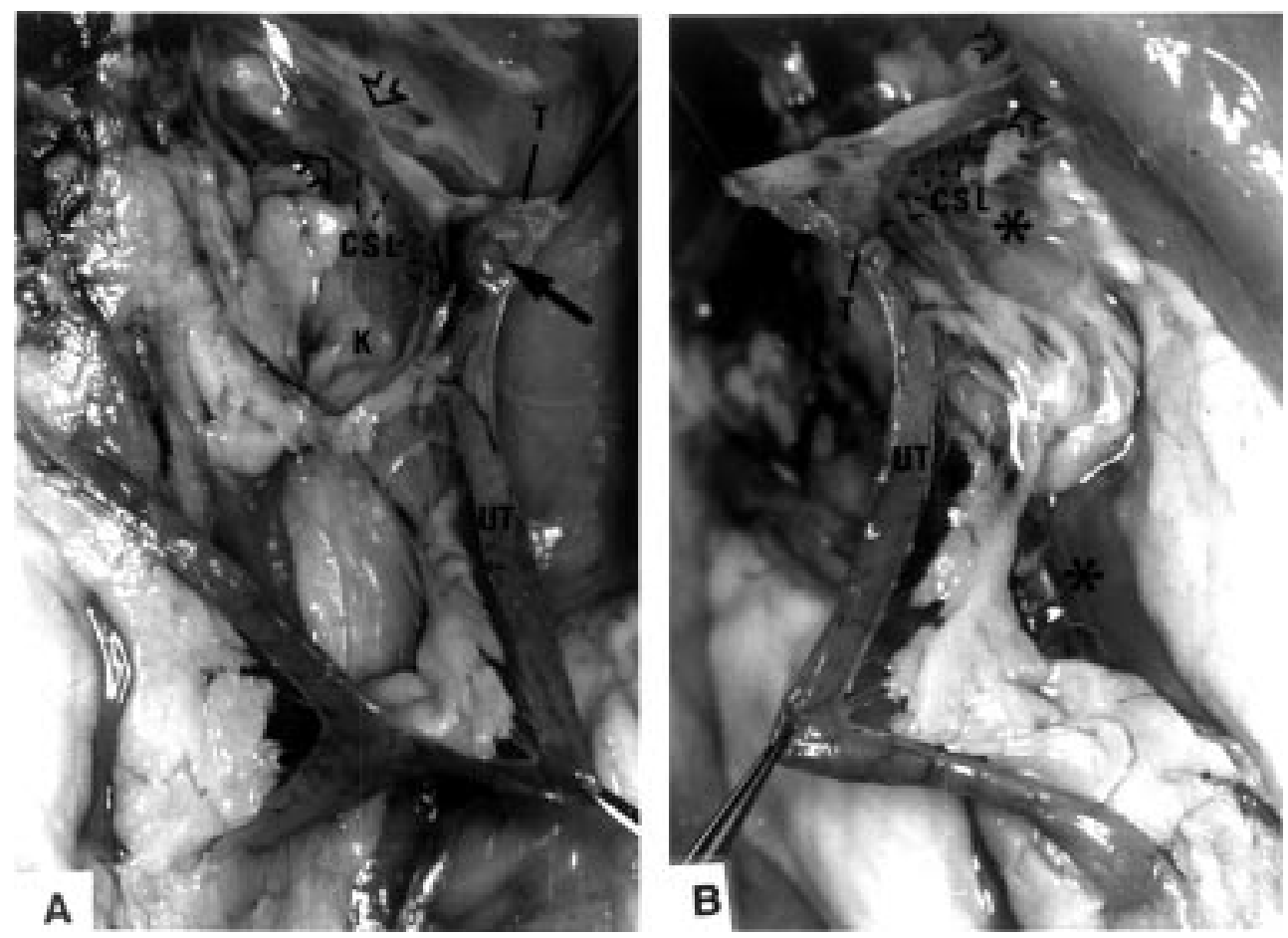

Figure 4. The medial (A) and lateral (B) aspect of the left genital apparatus in an adult female guinea pig. The cranial suspensory ligament (CSL) is a marked muscular strand (dotted lines) between the ovary (solid arrow) and the site of insertion in the area of the lowest ribs (arrowheads). During its course the CSL runs close to the lateral border of the kidney (K). The lateral aspect (B) reveals the whole of the mesentery (indicated with asterisks) between the genital apparatus and the dorsal body wall. The CSL appears as the anterior border of this mesentery. T $=$ Fallopian tube; UT = uterus.

female rats also (Figure 5) the CSL is a conspicuous structure. Cats and dogs are well known to show strong development of the CSL (Nickel et al., 1987; Dyce et al., 1996). In goats and other ruminants, the CSL has the shape of a broad and flat strand of muscular tissue between the ovary and the area of the diaphragm. In all these species the CSL appears, at closer inspection, not to emerge from the cranial pole of the ovary but rather from some site caudal to the ovary and along the cranial part of the uterus. As reported before (Melton and Saldivar, 1970; Gabella, 1976) and shown in Figures 4 and 5, the muscles of the CSL in guinea pigs and rats appear confluent with the uterine muscular wall close to the tubo-uterine junction.

Insectivores locate their ovaries at a low position in the abdominal lumen. Nevertheless, a CSL can still be identified, as shown in Figure 6, which presents pictures prepared from histological sections through the lower abdomen of a female and a male fetus of the hedgehog (Erinaceus europeus).

Pigs are exceptional, as their CSL runs across the ventral surface of the kidney (Figure 7). As described before, the mesonephros in this species shows development to an unusually large size and, indeed, during an early stage of development the abdominal lumen is almost completely filled with mesonephric tissue (Patten, 1948; Figure 8A).
Metanephric development results in ventral rather than lateral displacement of the mesonephric bodies and associated structures. During further development, mesonephric regression occurs while this organ is situated ventral rather than lateral to the metanephros. Accordingly, after mesonephric regression, all of the mesonephric remnants, including specifically the cranial mesonephric and the gonadal ligament, maintain a position on the ventral wall of the kidney (Figure 8B).

Adult human females do not possess an obvious CSL. During late fetal life, human fetuses undergo an unusual alteration in the configuration of the lower abdomen associated with the later development of an upright body position. Through the alteration in pelvic girdle anatomy, the base of the inguinal abdomen gains a ventral position, and the area below the kidney acquires the most caudal intraabdominal position, which is different from non-human mammals. Accordingly, the female gonads also acquire an unusually low intra-abdominal position below the pelvic brim. This alteration is reflected in the altered position of the rectum, which becomes displaced to the left; in nonprimate mammalian species the rectum runs across the midline of the dorsal abdominal wall. One could imagine that, due to the altered pelvic and genital position, the CSL becomes submerged within the peritoneum and subperi- 

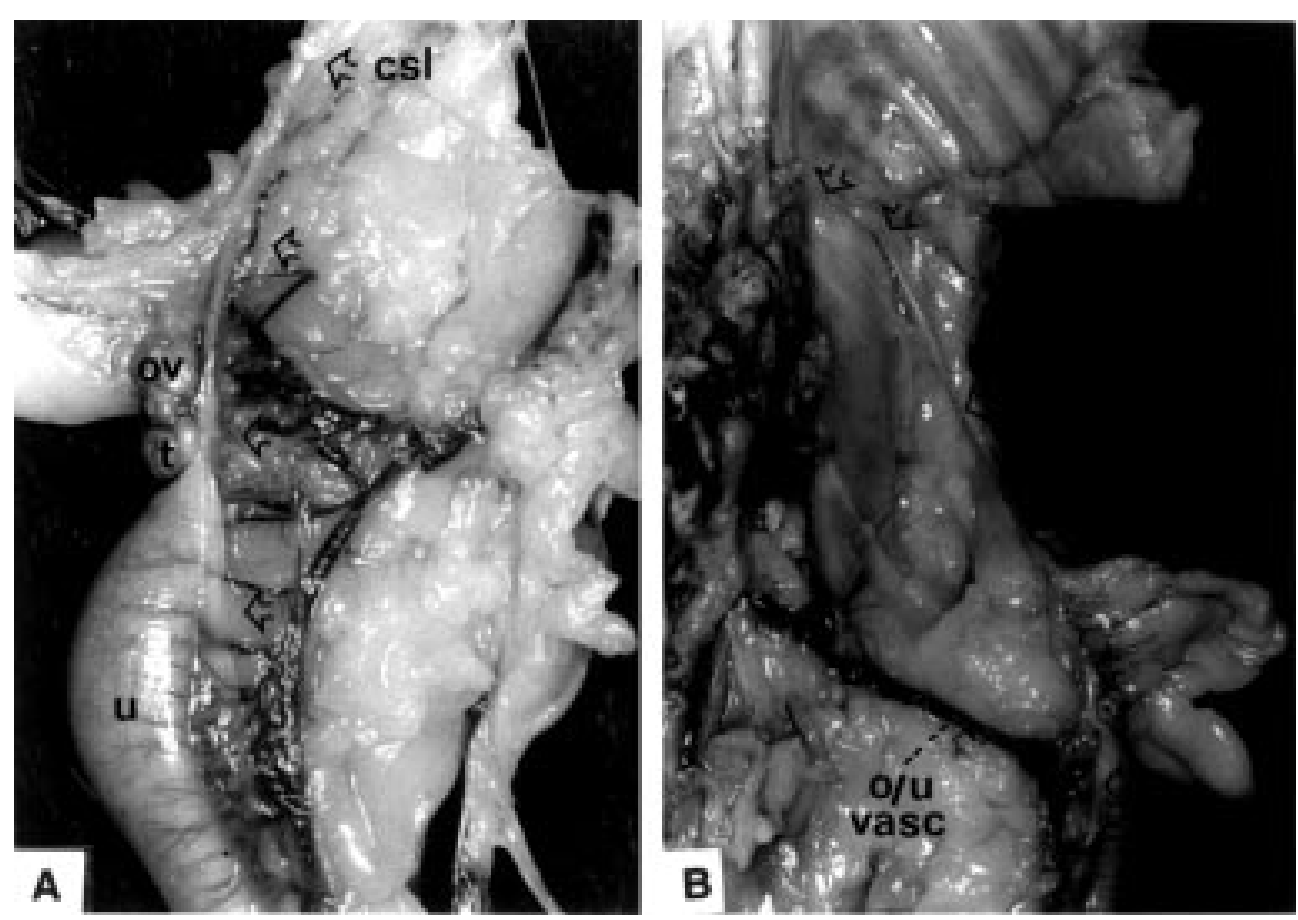

Figure 5. The isolated right (A) or in-situ left (B) genital system of an adult female rat after filling the blood vascular system with darkly staining resin (method described by Ciner et al., 1996). The cranial suspensory ligament (CSL) presents itself (A) as a long strand (arrowheads) from the cranial part of the uterus (lowest arrowhead) in the cranial direction. Fibres of the CSL are confluent with fibres of the upper part of the uterine wall. Insertion of the CSL occurs in the area of the lowest ribs (in B). The CSL in $\mathbf{B}$ has been visualized through the selective removal of the attached fatty tissues. $\mathrm{u}=$ uterus; $\mathrm{t}=$ Fallopian tube; ov = ovary; $\mathrm{o} / \mathrm{u}$ vasc $=$ the ovarian/uterine vascular stem.

toneal connective tissues lying craniolateral to the gonads. Indeed, extensive vasculature was found in the subperitoneal tissues craniolateral to the ovary in the body of an adult woman; no such vasculature was observed in this area associated with testes in males (P.van der Schoot and J.M.A.Emmen, unpublished observations). Furthermore, female human fetuses with advanced development may show the unequivocal development of the CSL, while no such structure remains recognizable in male fetuses of the same age (England, 1990). A beautiful example of this has remained unnoticed for a long time in the Hunterian collection of the Department of Anatomy in the University of Glasgow, Scotland (Figure 9).

\section{Exceptions to a rule: marked CSL development in male mammals with testis descent}

Male mammals with testis descent generally show inconspicuous or absent development of the CSL primordia beyond an early stage of fetal life. Exceptions to this general rule have been described in studies of the genital anatomy of bats. One spectacular example is demonstrated in Figure 10 from a report of the genital anatomy in sheathtail bats: in this species the epididymal tail remains at the bottom of the sac-like processus vaginalis throughout its lifetime. The testes, however, have only a temporary descent into these sacs during the stage of the year in which active spermatogenesis occurs (Jolly and Blackshaw, 1988). Outside this period, they remain contained within the abdominal lumen through contraction of the CSL, which reportedly possesses extensive muscular development. Although the extensive muscular development of the CSL in this species may be unique, its persistence in males of other species of bats has also been described (Krutzsch, 1979). Bats thus demonstrate in a very peculiar and unique fashion the difference which exists between the testicular ligamentum connecting the testis to the epididymis and the gubernacular ligaments connecting the lower aspect of the epididymis to the bottom of the processus vaginalis. Also, they show a 'physiological' association between the size (length) and strength of the muscular CSL and the localization of the testes in an intra- or extra-abdominal site with the consequence of the absence or development, respectively, of spermatogenesis.

\section{Further exceptions to the rule: development of the CSL in species with testicondia}

Testis descent is a feature specific to mammals, but not all mammalian species show this event. Absence of testis 

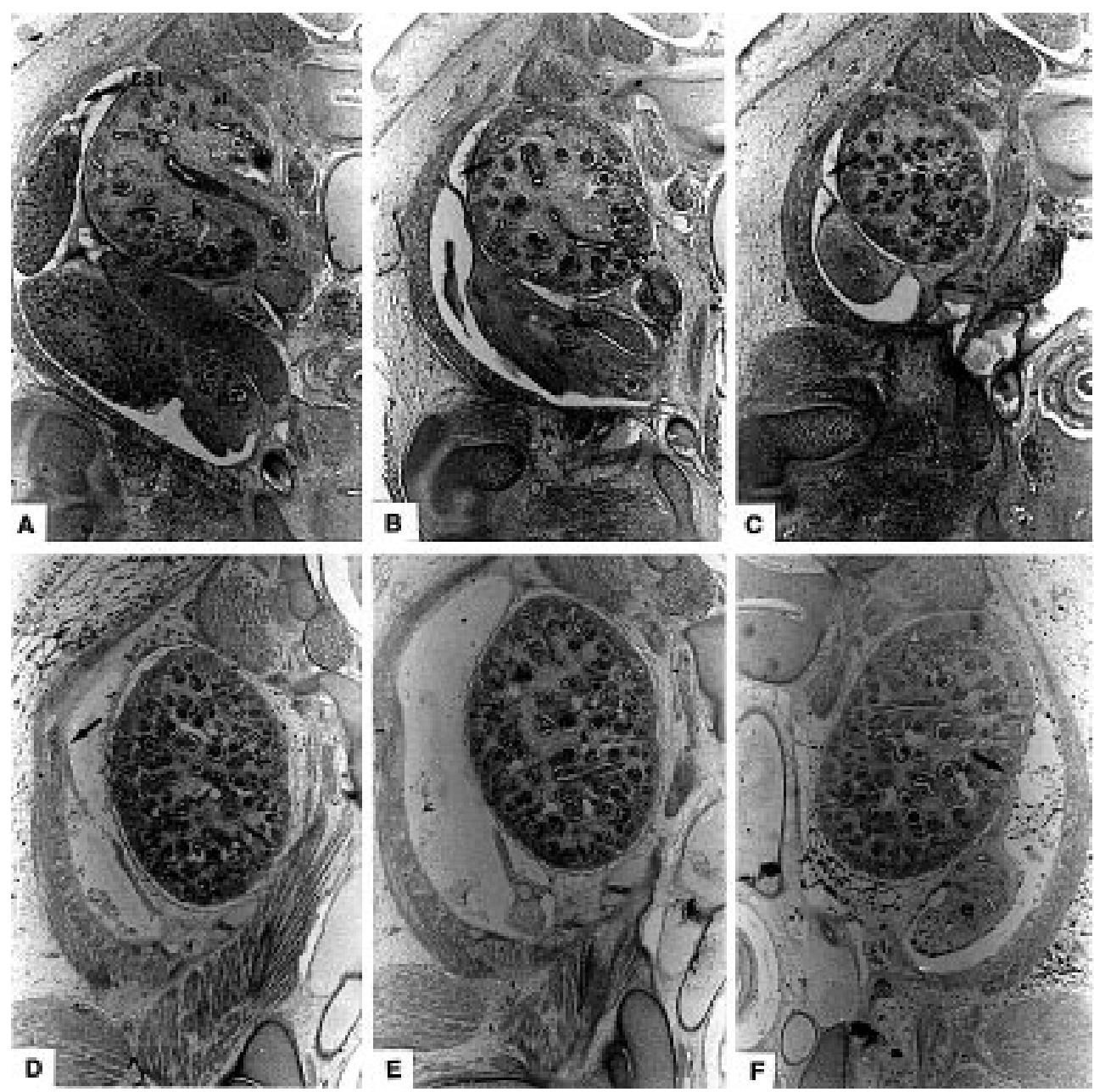

Figure 6. (A-F) Transverse sections through the lower abdomen of an Erinaceus europeus fetus (from the collection at the Hubrecht Laboratory for Developmental Biology, Utrecht, The Netherlands). In the female specimen (A-C) the cranial tip of the cranial suspensory ligament (CSL; solid arrows) is noticeable at the level of the cranial tip of the ovary. In the male fetus (D-F) the CSL only appears below the level of the testis (solid arrows in $\mathbf{D}$ and $\mathbf{F}$; in $\mathbf{F}$ ending as part of the kidney capsule). Both male and female gonads develop close to the bottom of the abdominal cavity and their position is thus markedly different from rodents and most other mammals. $\mathrm{OV}=$ ovary; $\mathrm{M}=$ mesonephros; $\mathrm{K}=\mathrm{kidney} ; \mathrm{E}=$ epididymal caput (in $\mathbf{F}$ ).

descent has been called testicondia (Weber, 1898) and noticed in a wide variety of species (Freeman, 1990), i.e. among the cold-blooded evolutionarily old mammals such as the Monotremata, Edentata, several species of Insectivora, Cetacea and among three related orders of warm-blooded mammals called collectively Paenungulata (the Sirenia, Hyracoidea and Proboscoidea).

Testicond males of the Monotremata and Edentata show obvious development of the CSL (Weber, 1927/28; Raynaud, 1969; Goffart, 1971; Griffiths, 1984). Testicond hyrax and elephants have intra-abdominal testes connected at their cranial side to the lower pole of the kidney, and this structure includes a CSL (Weber, 1927/28; Schulte, 1937; Frade, 1955); this anatomical situation in elephants persists from prenatal development (Eales, 1929).
Cetacea show intra-abdominal retention of the testes throughout their lifetime. Testicondia in these species is judged to have evolved secondarily as part of the anatomical adaptations of their ancestors to a return to aquatic life. So-called secondary testicondia in these species is associated with stunted development of the gubernacular primordia and, in fact, a processus vaginalis never develops (van der Schoot, 1995). The CSL persists to a variable extent in several cetacean species, but its size in males seems less than in female conspecifics: the generally large size of cetacean testes may require indeed additional suspensory support at their cranial pole through the CSL (Weber, 1927/28; Slijper, 1966; de Smet, 1977).

Primary testicondia in the evolutionarily oldest mammals (Monotremata, Edentata) includes a pattern of genital 

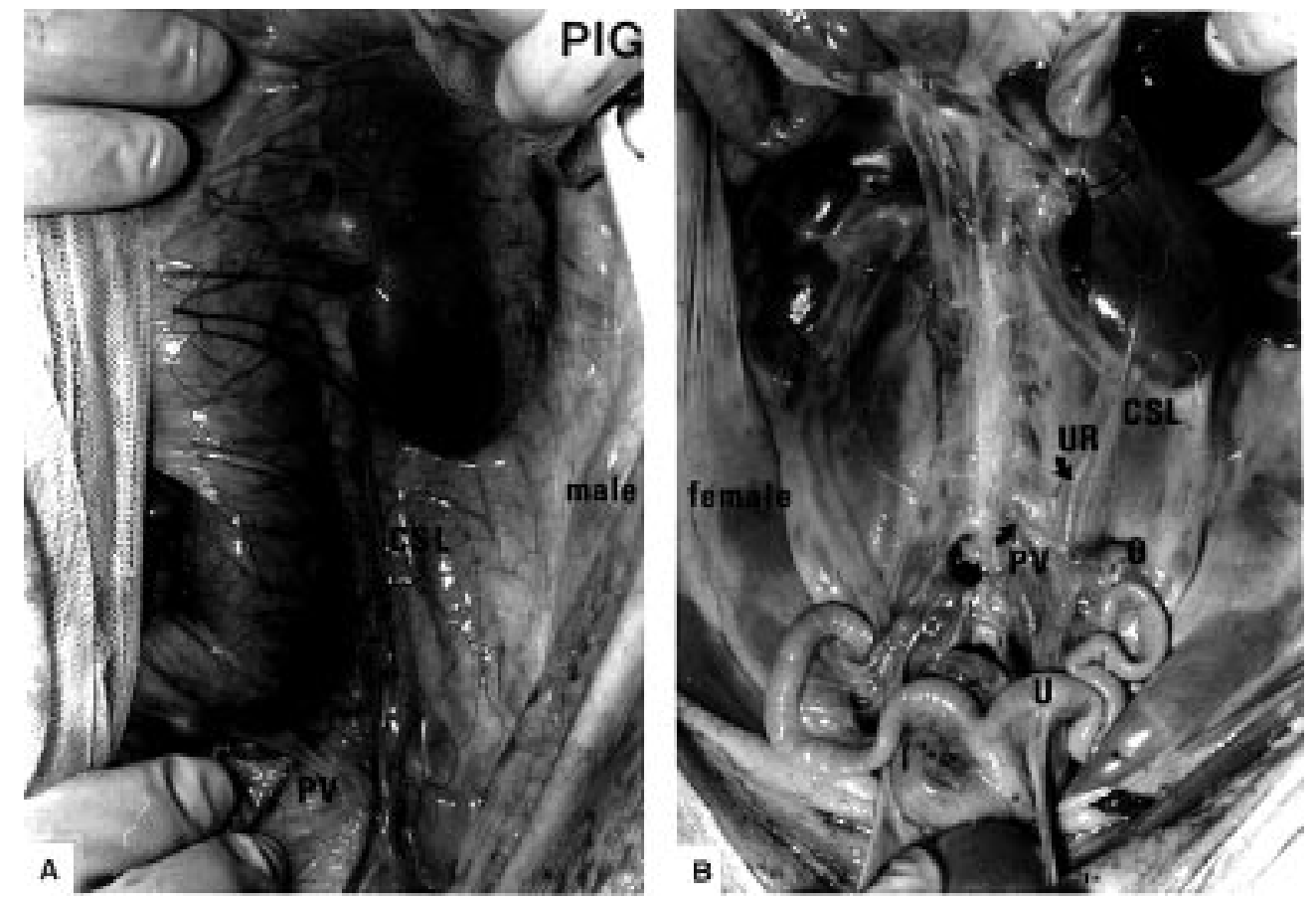

Figure 7. A view into the lower abdomen of a 100 day old neonatally castrated male (A) or female (B) pig. The male shows a minor vascular plexus (PV) with which the testes had been connected to the body midline. The PV is different from the cranial suspensory ligament (CSL), which is an easily recognizable structure between the area of the internal inguinal ring (the processus vaginalis had been removed during neonatal castration) and cranial part of the mesentery. The male CSL does not touch the kidney. In the female, an easily identifiable CSL crosses the kidney surface on both sides. The CSL are structures that are different from the ovarian/uterine vascular plexus $(\mathrm{PV})$ and ureter $(\mathrm{UR})$. $\mathrm{O}=\mathrm{ovary}$; $\mathrm{U}=$ uterus; $\mathrm{K}=$ kidney.

A

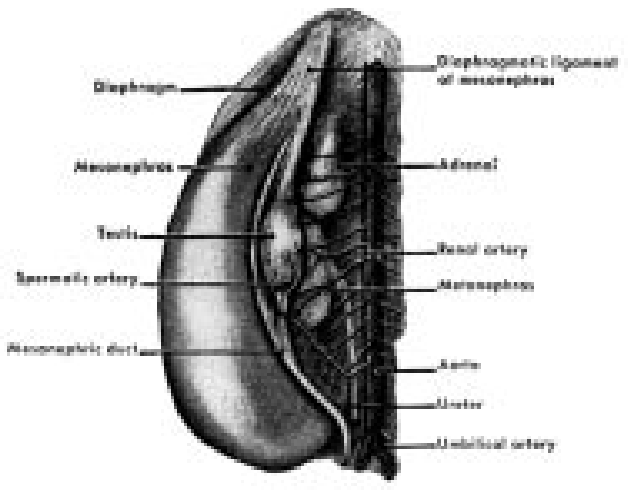

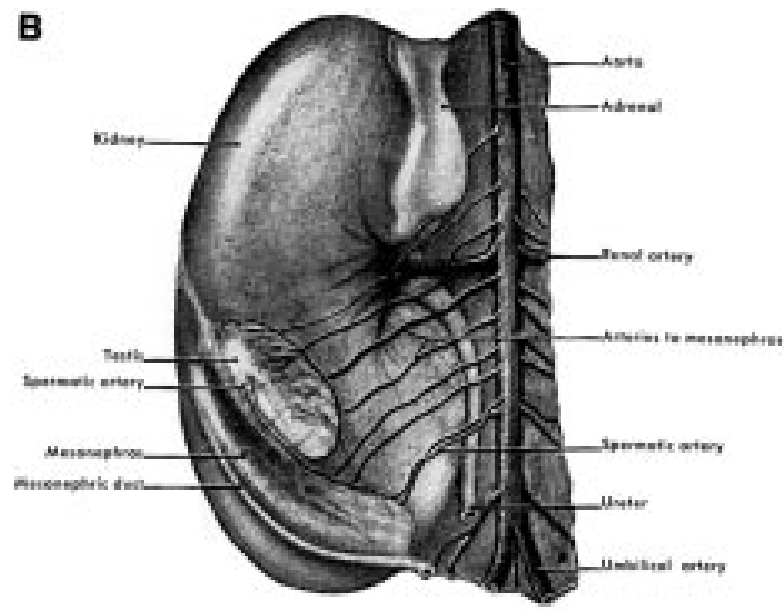

Figure 8. Two stages of early fetal development in pigs (reproduced, with permission from the publishers, from Patten, 1948). The $33 \mathrm{~mm}$ fetus (A) demonstrates the relatively enormous size of the mesonephros during early developmental stages in this species. The arterial blood supply still includes the ligament cranial to the developing gonad. The mesonephric duct runs across the ventral surface of the mesonephros, which is unusual as this occurs on the lateral border of this organ in most other species. In the larger fetus (B), lateral displacement of the mesonephros through the enlarging kidney occurs in a different way compared with most other species in that the gonad and mesonephric remnants remain situated on the ventral aspect of this organ. These unusual features explain the unusual position of the cranial suspensory ligament (CSL) as described in Figure 7. The CSL is devoid of vascular connections with the body midline.

anatomy which is essentially similar to that of submammalian vertebrates (reptiles and birds), and persistence of the CSL should be of no surprise. Insectivora such as Tenrec, Chrysochlorus and Elephantulus show intra-abdomi- nal testes close to the caudal pole of the kidney and these organs are provided with a CSL at their cranial tip (Grassé, 1955; Eckstein and Zuckerman, 1960). Insectivora with an obviously developed inguinal genital mesentery and testes 


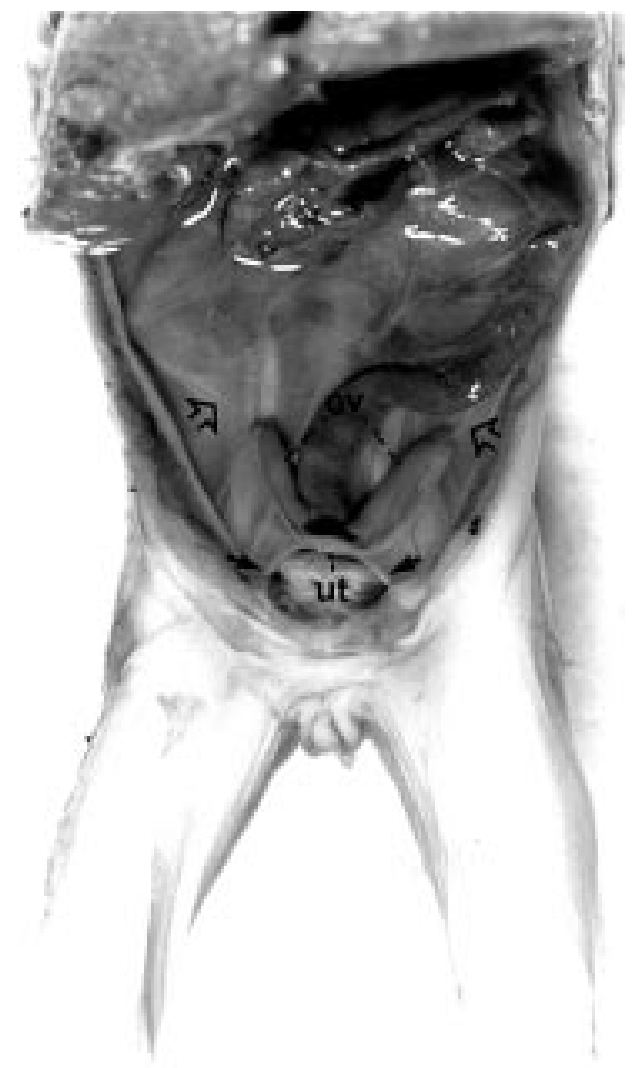

Figure 9. The development of the cranial suspensory ligament in a 5 month old human female fetus. This picture was obtained, through the kind cooperation of Professor A.P. Payne (University of Glasgow, Department of Anatomy, Glasgow, Scotland, UK), from specimen number 44.14 of the Hunterian Collection in Glasgow. ov = ovary; ut = uterus; arrowheads = cranial suspensory ligaments; solid arrows $=$ uterine round ligaments.

which are fixed 'by a stout ligament, in pouch-like extensions of the caudal end of the abdominal cavity' do not show a cranial CSL (Pearson, 1944). Primary testicondia in Paenungulata (elephant, hyrax and sirenia) is associated with limited to absent outgrowth of the genital mesenteric fold in the inguinal direction and, in hyrax, with insertion into the lateral bladder ligament (van der Schoot, 1996a). These species further show extensive 'female-like' development of the genital broad ligaments; the inguinal mesenteric fold, if present at all, may be insufficient to anchor the gonads and genital ducts appropriately to the dorsal abdominal wall, thus necessitating further support by the persistent CSL (Weber, 1927/28).

\section{Hormonal control of suppressed development of the CSL in males}

In the absence of specific research interests in the CSL it was unclear, until recently, whether absence of the CSL in males of most mammalian species (Hamilton et al., 1962)

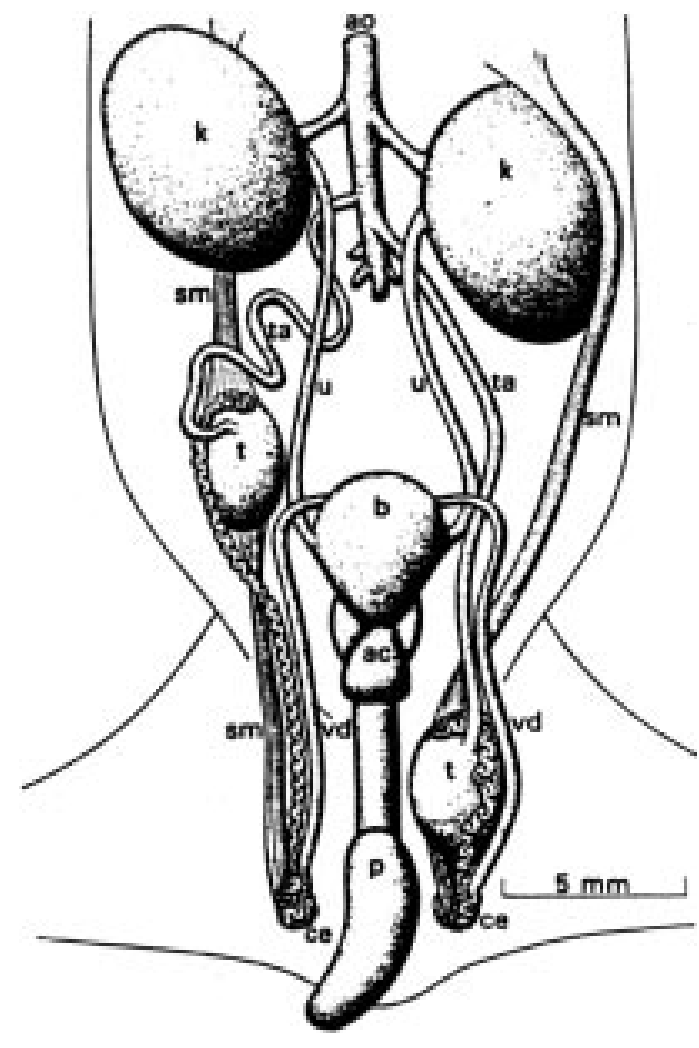

Figure 10. Schematic drawing of the urogenital system of an adult male sheath-tail bat (reproduced, with permission of the publishers of the Journal of Reproduction and Fertility, from Jolly and Blackshaw, 1988). The right part of the picture shows the descended testis at the time of the year in which active spermatogenesis occurs. The cranial pole of the testis is connected with the area of the diaphragm through a muscular strand. Contraction of this strand causes re-entrance of the testes into the abdominal cavity (as shown with the other testis). The cranial suspensory ligament presents itself herewith as a structure completely distinct from the ligament between the caudal pole of the testis and the epididymis (to be considered as the ligamentum proprium). $\mathrm{k}=$ kidney; $\mathrm{ao}=$ aorta; $\mathrm{t}=$ testis; $\mathrm{sm}=$ cranial ligament; $\mathrm{u}=$ ureter; $\mathrm{ta}=$ testicular artery; $\mathrm{b}=$ bladder; $\mathrm{ac}=$ accessory gland complex $; \mathrm{vd}=$ vas deferens $; \mathrm{ce}=$ epididymal cauda $\mathrm{p}=$ penis .

was to be judged the consequence of specific fetal testicular hormonal action or just the 'passive consequence' of the smoothing of the mesentery cranial to the tip of the gonads along the whole of the dorsal abdominal wall, in view of the absence of specific female structures such as the tip of the paramesonephric (Müllerian) ducts.

The first step indicating specific hormonal control of the suppression of CSL development during male mammalian fetal life resulted from an analysis of genital development in male rat fetuses exposed to the anti-androgen flutamide and in female fetuses exposed to androgen (methyl-testosterone) via injections of the respective compounds into their mothers during pregnancy (Figure $11 \mathrm{~A}-\mathrm{C}$; van der Schoot and Elger, 1992). Detailed investigations of older papers then revealed that suppression of CSL development 

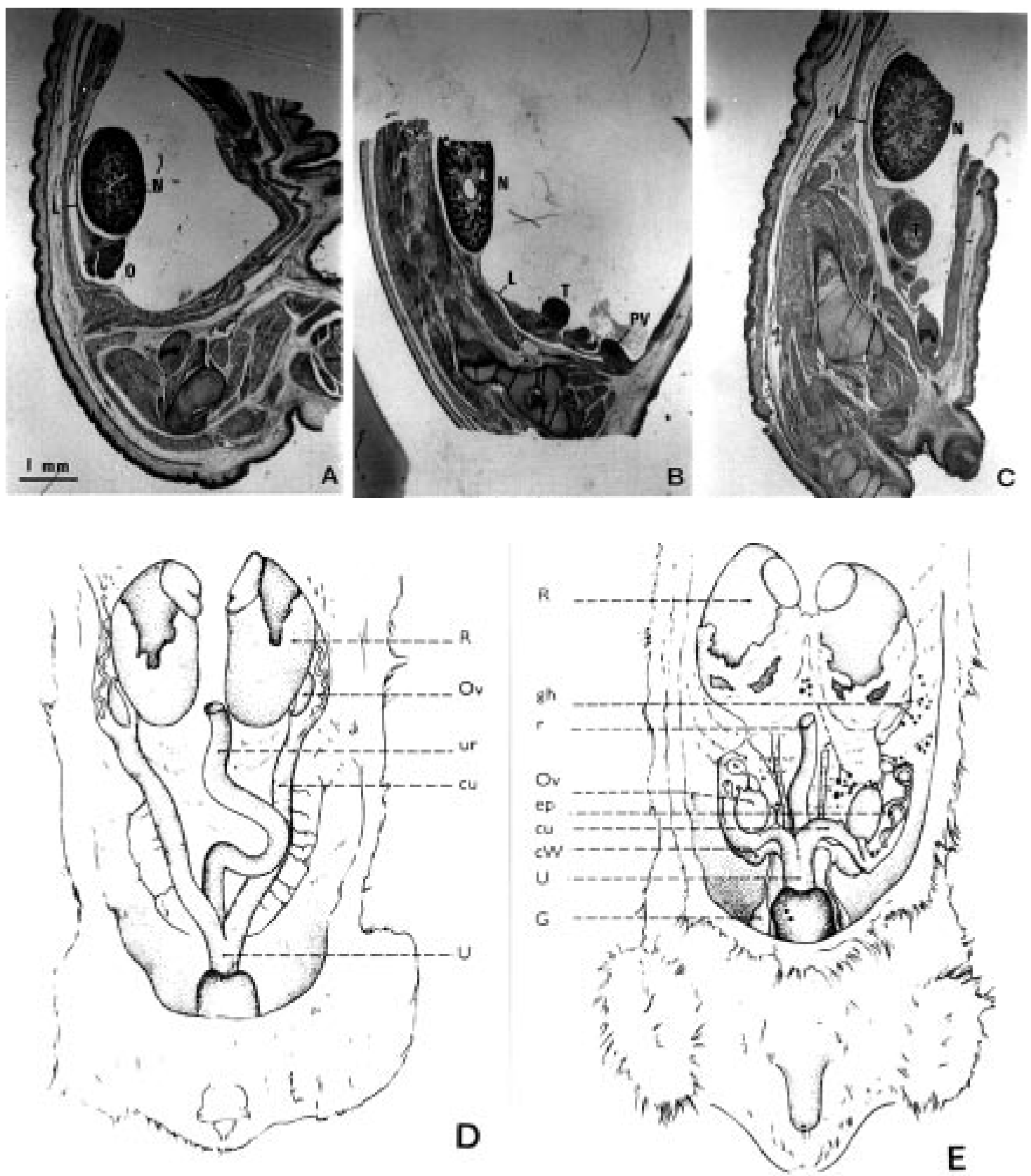

Figure 11. (A-E) Sagittal sections through rat fetuses (A-C) on day 20 postconception and new-born guinea pigs (D and $\mathbf{E})$. The female rat fetus (A) shows a marked cranial suspensory ligament (CSL; indicated by L) between the ovary $(\mathrm{O})$ and the area cranial to the kidney $(\mathrm{N}$ in $\mathbf{A}-\mathbf{C}$; $\mathrm{R}$ in $\mathbf{D}$ and $\mathbf{E})$. The male fetus (B) does not show such structure. In a male exposed to flutamide from day 10 after conception $(\mathbf{C})$ development of the CSL has occurred in a similar fashion to that in the female fetus. In both male fetuses the gubernacular cone (PV) has developed similarly and no such structure develops in females. A control new-born female guinea pig (D) shows ovaries (Ov) lateral to the kidneys and connected to the area cranial of the kidneys with the CSL. Exposure of female fetal guinea pigs to timed injection of androgen (E) causes marked reduction of the CSL and, specifically, no extension of this structure beyond the caudal pole of the kidney. [D and $\mathbf{E}$ have been reproduced from work published by Dantschakoff (1941), with permission of the publishers of these pictures: Masson, Paris]. ur and $r=$ rectum; cu and $U=u t e r u s ; ~ e p=e p i d i d y m i s ;$ $\mathrm{cW}=$ Wolffian duct.

through prenatal exposure of females to androgen had been observed earlier, but the significance of the observation had remained unnoticed (Figure 11D and E; Greene et al., 1938; Dantschakoff, 1941). In freemartins, there appears to be unrestrained development of a female-type CSL (Figure
12); in contrast, exposure of female bovine fetuses to exogenous androgen during fetal life resulted in reduced CSL development (Jost et al., 1963; Figure 13).

Suppression of androgen action during fetal life in rats was reported to result in development of the CSL in a 

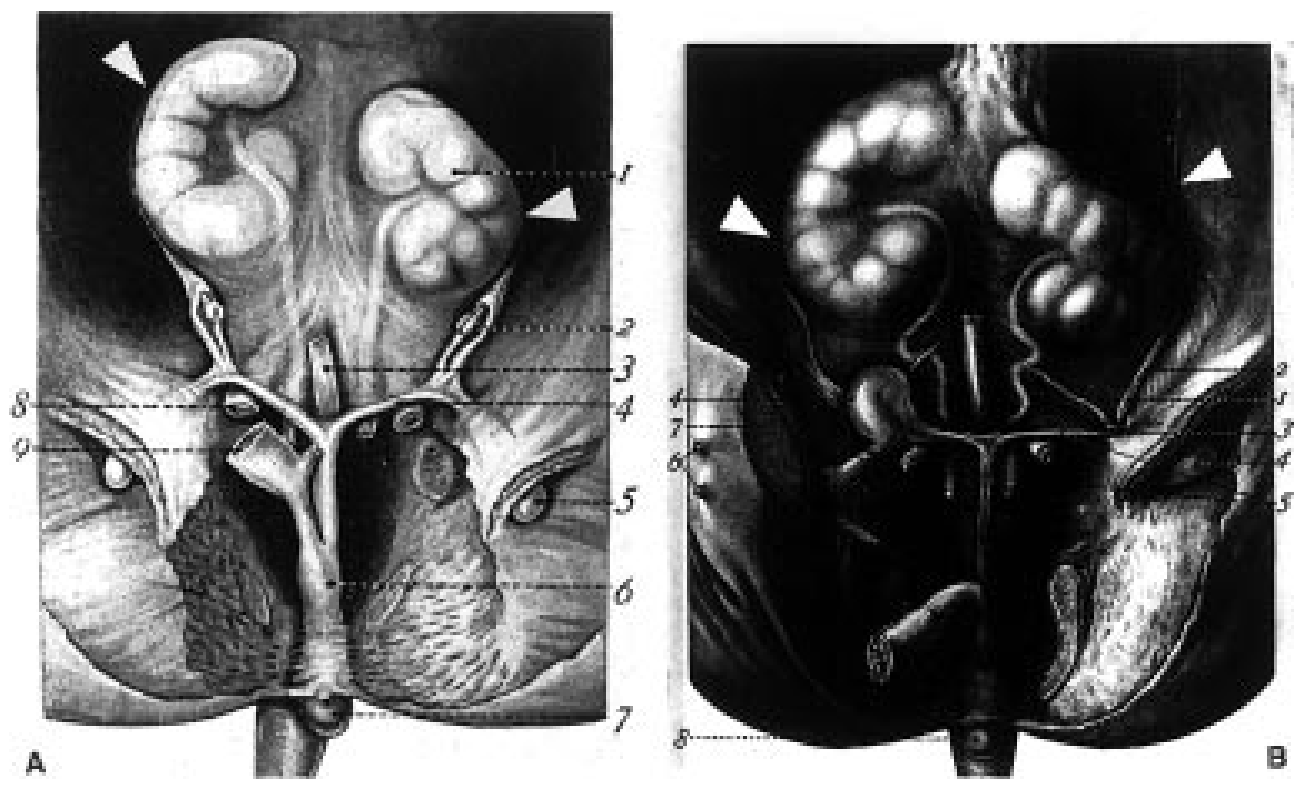

Figure 12. (A and B) Development of the cranial suspensory ligament (CSL) associated with bovine freemartinism. During an early stage of fetal development, freemartins show male-like outgrowth of gubernacula (indicated by 5 in $\mathbf{A}$ and 4 in $\mathbf{B}$ ) together with female-like persistence of the CSL (white arrows; indicated by 2 in $\mathbf{B}$ and easily distinguishable on both sides in A). During further development, CSL growth continues in a cranial direction. This further growth of the CSL occurs while these latter are connected, indirectly, to the bottom of the developing gubernacula. The result (in B) is the inversion of the gubernacula into papilla-like prominences upon the inguinal abdominal base (the structure indicated by 4 on the right side of $\mathbf{B}$ ). Reproduced from Lillie (1917) with kind permission of the publishers.

female-like fashion (van der Schoot and Elger, 1992; Spencer et al., 1994). Male mice affected by the testicular feminization mutation show intra-abdominal testis retention and these testes also show a clear CSL at their cranial tip (Hutson, 1986; P.van der Schoot and J.M.A.Emmen, unpublished observations). Earlier investigations had already reported the presence of cryptorchidism after prenatal exposure to anti-androgens, but a possible relationship with CSL development remained unnoticed (Husmann and McPhaul, 1991; Spencer et al., 1991; van der Schoot, 1992b). Development of the CSL, together with a tendency towards crytorchidism during postnatal life, was also noticed after prenatal exposure to flutamide in pigs (McMahon et al., 1995).

Male-specific differentiation of the internal genitalia is generally thought to become effected through exposure of their primordia to fetal testicular testosterone or other androgenic steroids (Wilson et al., 1981) or anti-Müllerian hormone (AMH; Josso et al., 1993). There is no evidence to indicate that $\mathrm{AMH}$ could play a role in male differentiation of the CSL (Baarends et al., 1994; Behringer et al., 1994). Male-specific differentiation of the genital primordia is generally judged to depend on exposure to testis hormones during an early 'critical period' of development. Before or after such a period, testis hormones are unable to affect the development of the primordia in a male-typical fashion. Androgenic effects on the developing CSL are also limited to a 'critical' early period of development: Dantschakoff (1941) reported that, beyond 25 days after conception, androgen in guinea pigs was ineffective in the suppression of CSL development. Earlier work with rats indicated that postnatal exposure to the anti-androgen flutamide did not result in suppressed CSL development (van der Schoot, 1992a). However, postnatal injections might not be effective due to a compensatory increase in testicular testosterone secretion during treatment with flutamide (Peets et al., 1974; Södersten et al., 1975; Viguier-Martinez et al., 1983). Recent work in rats with timed exposure to $5 \alpha$-dihydrotestosterone at the end of prenatal life has revealed, however, that the 'critical period' in which an androgen can suppress CSL development has already ended, at day $\sim 17 / 18$ after conception (J.M.A.Emmen et al., unpublished observations).

Taking all the above arguments together, it is concluded that the developing CSL in rodents, cattle and pigs can be considered a 'classical' target organ for fetal testicular androgens and that the latter hormones have a function in sexual differentiation of the CSL primordia that is similar to that in differentiation of the Wolffian duct derivatives and genital tubercle. The action of androgens on the CSL primordia is unusual, since it appears that they act to inhibit development and/or differentiation of the CSL; androgen action on the remaining parts of the developing genitalia is generally considered to induce their stabilization and 
A
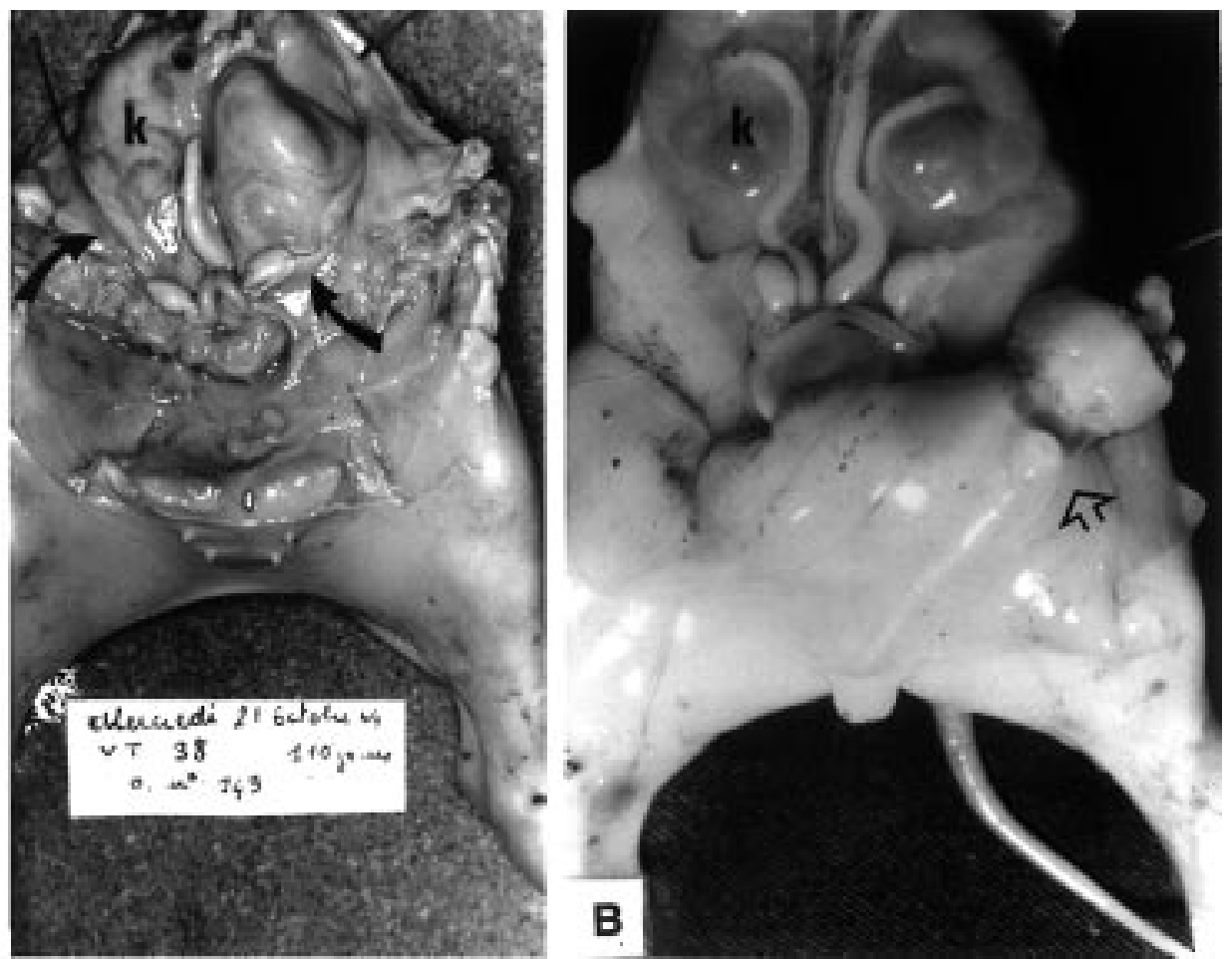

Figure 13. Development of the cranial suspensory ligament (CSL) on day 110 after conception in a control female bovine fetus (A) or a fetus exposed to androgen (via injection of methyl-testosterone into its mother from day 38 after conception) during early fetal life (B). In A, a distinct CSL (curved arrows) is easily distinguishable on both sides along the caudal border of the kidneys ( $\mathrm{k}$; see also Figure $1 \mathrm{C}$ and $\mathrm{D}$ ). In $\mathbf{B}$, there appears a markedly reduced CSL running well below the caudal pole of the kidneys (K). Androgen exposure caused the growth of a male-like penis (arrowhead in Figure B indicates its tip) and a scrotum (at the base of the penis between the hind legs). Pictures have been obtained from the legacy of the late Alfred Jost through the kind cooperation of B.Vigier (Université Pierre \& Marie Curie, Paris, France).

growth and to promote their differentiation. It remains for future investigations whether reasonable evidence can be obtained to support the notion that male-typical suppression of the development of the CSL primordia can be completely explained by their exposure to androgen during fetal life.

Suppression of the outgrowth of the CSL via action of fetal androgens does not occur in all mammalian species. Failure of androgens to suppress CSL development is obvious in bats and in males of the earlier mentioned species with primary and secondary testicondia and persistence of the CSL. As a further interesting example, androgens do not seem to suppress CSL development in the female spotted hyena; in this species, female genital development shows several 'male' features and these have been associated with gonadal production of androgens during the fetal period (Matthews, 1939; Lindeque and Skinner, 1982; Glickman et al., 1992; Yalcinkaya et al., 1993). Nevertheless, as described by Weber (1927/28), hyena ovaries show a 'normal' intra-abdominal position together with a well developed CSL running in a cranial direction. In males no such CSL develops.

\section{Development and persistence of the CSL as a potential key factor in the aetiology of cryptorchidism}

Bats provide an unexpected but excellent example that persistence and functional activity of the CSL can be an important determinant to maintain the testes in an intraabdominal position (Jolly and Blackshaw, 1988). In these animals the persistence of the CSL is unusual but clearly serves a distinct function to effect 'physiological' regression of testes into the abdominal lumen outside the annual period in which testicular spermatogenic activity occurs.

Persistence of the CSL in male rats, after their exposure to anti-androgens during fetal life, has been reported to lead to disturbed testicular descent (van der Schoot and Elger, 1993). There has developed some controversy as to whether the aetiology of such disturbed descent also includes an aberrant development of the gubernaculum: quantitative analysis of developing male fetuses revealed no reduction of its size in one study (van der Schoot and Elger, 1993), but minor reduction in size in another study 


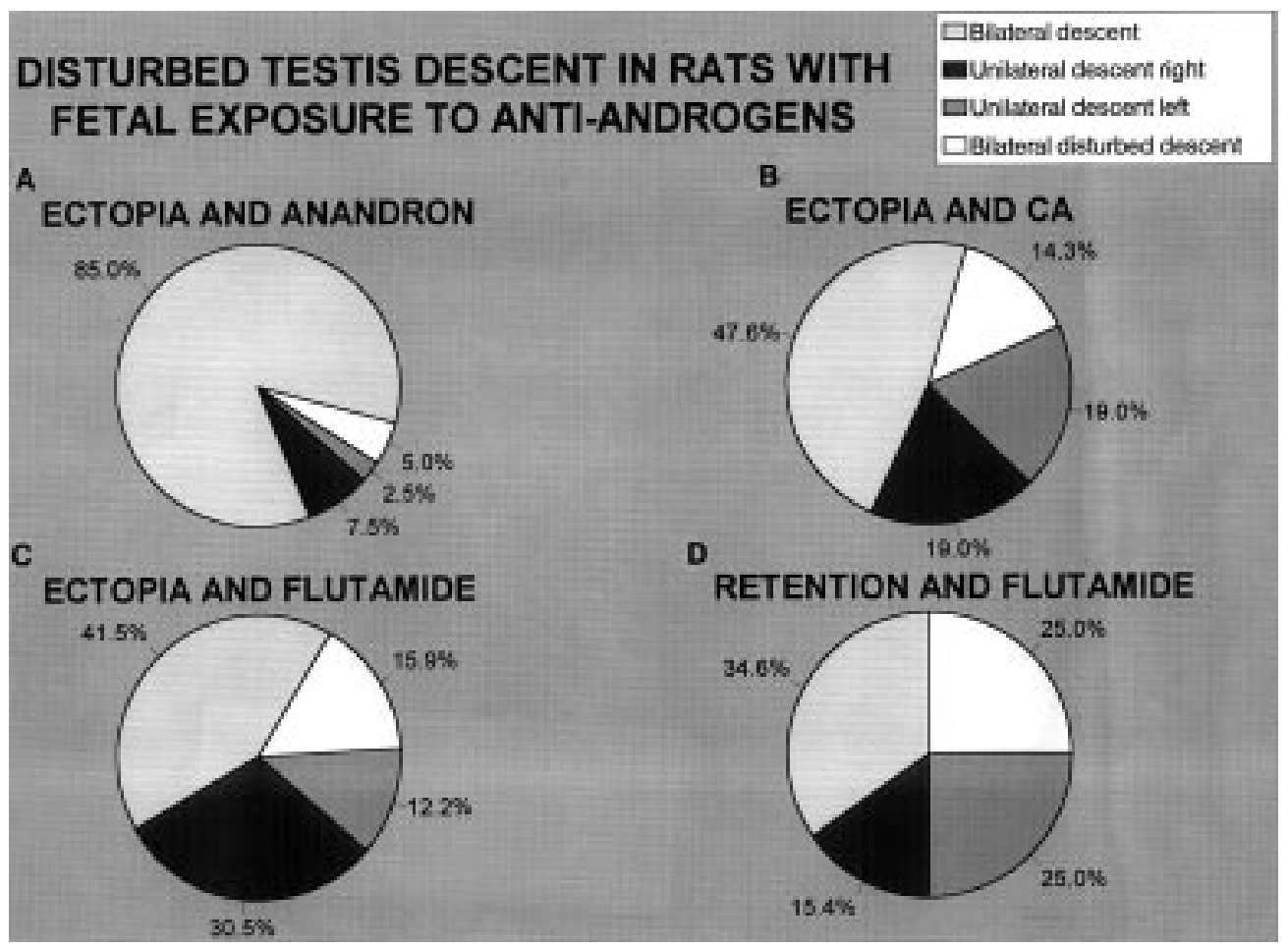

Figure 14. (A-D) Aberrant testicular descent in adult male rats exposed to anti-androgen during fetal life through daily injections of the compounds into their mothers from day 11 after conception. Anandron (Roussel-Uclaf, Romainville, France; $10 \mathrm{mg} / \mathrm{rat} / \mathrm{day} ; \mathbf{A}$ ) inhibited external virilization and caused ectopia in a minor number of animals. Cyproterone acetate (CA: Schering, Berlin, Germany; $10 \mathrm{mg} / \mathrm{rat} / \mathrm{day} ; \mathbf{B})$ also fully inhibited external virilization; however, postnatal development of the epididymis was hardly affected. Only a minority of the rats showed bilateral testicular descent. Administration of flutamide (Schering-Plough, Bloomfield, NJ, USA) in Wistar rats (10 mg/rat/day; $\mathbf{C}$ ) was effective in inducing a similar degree of aberrant testicular descent as cyproterone acetate. However, when the same dose of the same compound was administered to Sprague-Dawley rats, there was intra-abdominal retention of testes ('true cryptorchidism') and no testicular ectopia (in D). The latter two groups further differed markedly in the degree of interference with epididymal development. The majority of Sprague-Dawley rats had no such structure during adulthood. Bilaterally cryptorchid animals showed the virtual absence of epididymal remnants. In rats with retained epididymis, no cryptorchidism was observed.

(Cain et al., 1995). A further study revealed that, during the end of fetal and the onset of postnatal life, gubernacular size could become increased rather than decreased as compared with control or untreated male fetuses (van der Schoot and Elger, 1993; Spencer et al., 1994). Analysis of the morphology of such developing gubernacula indicated that exaggerated rather than reduced size could reflect intra-abdominal extension as the result of the gubernacula being pulled in the cranial direction through the persisting cranial ligaments.

Failure of androgen action during fetal life in rodents reportedly leads to two types of disturbed testis descent: intra-abdominal retention ('true cryptorchidism') or ectopia (aberrantly directed outgrowth of the processus vaginalis with a testis contained within them). Interestingly, in a study using flutamide exposure of Wistar rats, only ectopia occurred, whereas in a parallel study using the same compound in Sprague-Dawley rats intra-abdominal testis retention was noticed (Brand et al., 1989, Figure 14). Dur- ing these studies, both species of pregnant rat had been subjected to the same treatment regimen. Together with the different localization of the testes, there was more effective suppression of Wolffian duct derivatives in SpragueDawley male fetuses than in those of the Wistar strain. In both series of studies, exposure to flutamide did not affect male fetal development similarly in all cases. Between litters, within litters, and also within individuals genital development was variably affected. The result with Sprague-Dawley rats was similar to that reported by other groups using the same variety (Husman and McPhaul, 1991; Spencer et al., 1991).

Testicular ectopia has been reported earlier as one of the sequelae of fetal exposure to anti-androgen (Neumann et al., 1970; Peets et al., 1974; Habenicht and Neumann, 1983; van der Schoot, 1992b) and of androgen insensitivity in rats (Stanley et al., 1973). Disturbed descent is among the concomitants of the androgen insensitivity syndrome in animals and humans (Polani, 1970; Stanley et al., 1973; 
Spencer et al., 1994). In an inbred 'TS' rat strain, ectopia has been reported to occur to a considerable degree, but details of the remaining genital anatomy, including specifically the persistence of the CSL during perinatal or later life, have not been reported (Gärtner, 1969; Ikadai et al., 1988; Park and Hutson, 1991).

Disturbances in testicular descent together with persistence of the CSL may thus result from failure of androgen action during prenatal life in male mammals. The proposed mechanism of the dual outcome of these disturbances is schematically shown in Figure 15. Once this hypothesis had emerged from investigations with rats it became of interest to examine the potential broader picture among other mammalian species. Persistence of the CSL via an as yet unclear mechanism was found recently in a dog with intra-abdominal testes. Whereas no specific aetiological factor could be postulated to account for this persistence, there seemed an obvious relationship between persistence of the CSL and 'true cryptorchidism' in this specimen (Kersten et al., 1996). Examination of a neonatal pig with intra-abdominal testis retention revealed a similar association with retention of the CSL (Figure 16; P.van der Schoot et al., unpublished observations).

Ongoing work with fetal rats has revealed that androgendependent failure of growth or differentiation of the CSL primordia is one of the first aspects of the male genital differentiation processes. Persistence after a certain period during fetal life renders these primordia refractory to suppressive actions of androgens (J.M.A.Emmen et al., unpublished observations). Thus, the failure of early androgen secretion by the testes could become manifest only by inappropriate outgrowth of the CSL, with disturbed descent as the only consequence. It will be a matter of future research to find out to what extent failure of androgen-induced stunting of CSL development is among the aetiological factors responsible for aberrations in testicular descent.

\section{Human male and female development of the CSL}

Genital development in humans is different from that of most other mammals in many aspects. There are arguments to support the notion that the human uterine teres or round ligament is a developmental novelty (van der Schoot, 1996b): its mere mention as the uterine round muscle clearly supports this difference, as in many other species (rodents, but also ruminants) nothing similar is distinguishable across the uterine broad ligament. The uterine teres ligaments in humans and other primates provide a suspensory support for this organ for which there is no equivalent in non-primate mammals. Major suspension thus takes place at a level below the pelvic brim, at a considerable distance from the cranial tip of the abdominal cavity.

The development of alternative structures for genital suspension occurred simultaneously with development of the uterus into a single organ with a medial position in the lower abdominal cavity. These two features together might explain why the CSL in postnatal human females is no longer a conspicuous anatomical entity. During adulthood, remnants appear occasionally at the cranio-lateral pole of the oviduct (P.van der Schoot, unpublished observations; Rouvière, 1932; Romanes, 1981). This does not mean, however, that development and sexual differentiation of male and female CSL is fundamentally different between humans and other mammals. Figure 9 shows beyond doubt the persistence of the CSL in a 5 month old female fetus. In males of similar age no such structure persists any more (England, 1990; P.van der Schoot, unpublished observations).

The sex difference in human CSL development may be demonstrated in the future through the appropriate analysis of genital anatomy in human fetuses or in more developed specimens affected by one of the various syndromes of intersexuality. It might become clear, for example, that testes in the complete but not in the partial androgen insensitivity syndrome are attached 'unusually' strongly to the dorsal abdominal wall. To the contrary, ovaries in the syndrome of congenital adrenal hyperplasia may be unusually loosely attached to the dorsal wall. No data are available as yet concerning these two points.

The sex difference in human CSL development may aid the understanding of a specific anatomical feature of the syndrome of persistent Müllerian ducts (PMDS patients), i.e. so-called transverse testicular ectopia with both testes present in the same processus vaginalis. Males affected with PMDS show persistence of Müllerian duct derivatives together with normal male differentiation of the Wolffian duct derivatives. Descriptions of the genitalia of affected individuals show wide agreement with regard to the unusual mobility of the Müllerian duct derivatives and gonads from the dorsal abdominal wall (Josso et al., 1993). In fact, such individuals are sometimes diagnosed by the development of a unilateral scrotal masse which, at closer inspection, appears to include the whole of the Müllerian ducts derivatives and two testes (Stallings et al., 1976). From a normal female genital developmental perspective, there could be no reason why the uterus and attached structures become loosely attached to the dorsal abdominal wall. However, from the point of view of androgendependent suppressed development of the CSL, one might envisage that such loose development could take place. Further and specific anatomical investigations of males affected by PMDS may provide evidence in support of the 

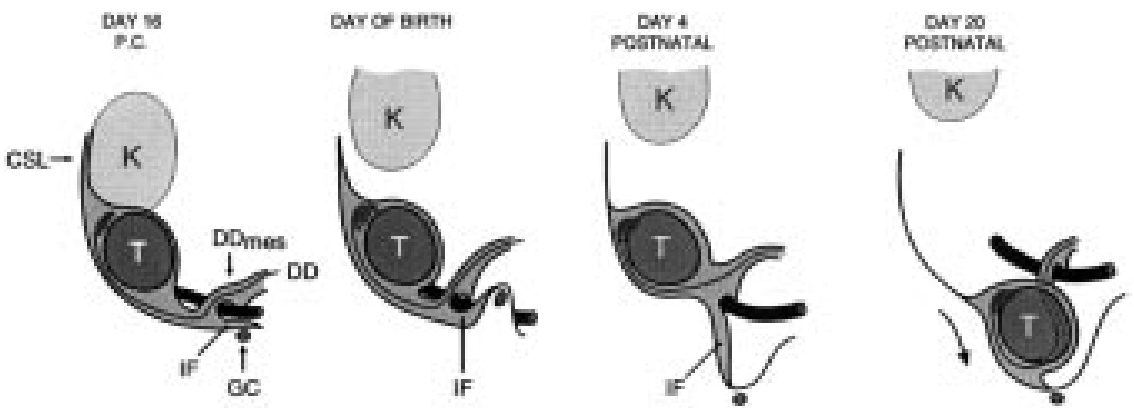

CTR
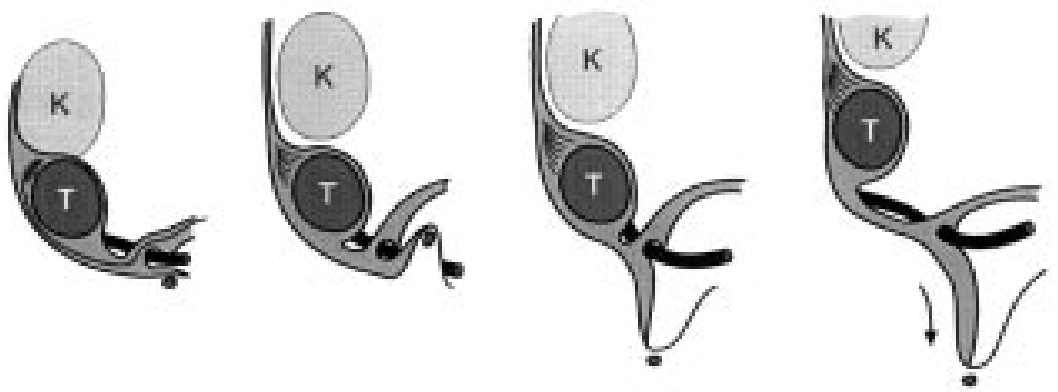

\section{AA \\ intra-abdominal retention}

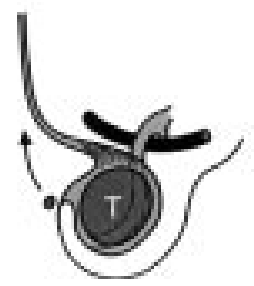

AA

ectopia Anti-androgens and disturbed testis descent

Figure 15. Proposed sequence of events during fetal and early postnatal development of the cranial suspensory ligament (CSL) and the gubernacula in control rats (CTR, upper row) and rats exposed to the anti-androgen flutamide during fetal life (AA, second row). Between day 16 after conception and day of birth the gubernacular cones (GC) develop into papilla-like structures which serve, with their tip and posterior aspect, as the site of insertion of the inguinal fold (IF) of the genital mesentery. The CSL does not grow out in control rats, but does in anti-androgen-exposed fetuses. Development of the Wolffian duct derivatives (dark line with DD at its end in upper left picture) is suppressed through anti-androgen action. Postnatally, inversion of the papilla-like GC occurs in both groups of animals. During further outgrowth, the epididymis and attached testis gradually descend into the thus emerging processus vaginalis in control animals. Descent is hampered in anti-androgen-exposed animals. The persistent CSL might inhibit testes from reaching the sac-like processus vaginalis and they then become connected with the base of the latter structure via an elongated inguinal fold of the genital mesentery (intra-abdominal retention; last picture of second row). The persistence of the CSL might also interfere with proper descent in a different way. Its connection, through the gonadal ligamentum proprium and the inguinal fold of the genital mesentery, with the base of the developing processus vaginalis (third picture of the second row) may result in further aberrant growth of the processus vaginalis. Outgrowth of the free wall of the emerging processus vaginalis ventrally, together with the dorsal wall occupied by genital mesenteries, may result in a situation comparable to that in which inappropriate penile outgrowth underlies development of a curved penis with ventral chordee. The aberrant (curved) outgrowth of the processus vaginalis may easily lead to further outgrowth of its tip in an aberrant direction (the picture in the third row). It should be kept in mind that the processus vaginalis is essentially a structure that freely seeks its path through the loose tissues caudal to the external inguinal ring (Lillie, 1917; van der Schoot et al., 1995). Aberrant descent affects only $~ 50 \%$ of the testes in exposed animals. Seemingly normal testis descent may thus also occur, despite afflictions imposed upon the developing genital system through exposure to anti-androgens.

latter notion. Indeed, variation of CSL development may be a major factor controlling the degree of mechanical restraint upon the Müllerian duct derivatives to prevent them from 'falling aside' into the normally developed processus vaginalis of the right or left side (Josso et al., 1983). In this respect, it is worth mentioning that mice with PMDS syndrome as the result of genetic modification do not show persistence of their CSL but have 'normal' bilateral descent of the testes into sac-like processi vaginales (Behringer et al., 1994).

\section{Concluding remarks}

The present review is intended to attract attention to the presence of CSL in the internal genitalia as a normal part of the genital system throughout the vertebrate phylum, but with specific features in mammals associated (i) potentially with the requirements for maintenance of pregnancy in females and (ii) more obviously with testis descent in males. In female mammals, the CSL generally gains a specific extent through its function to suspend and support 

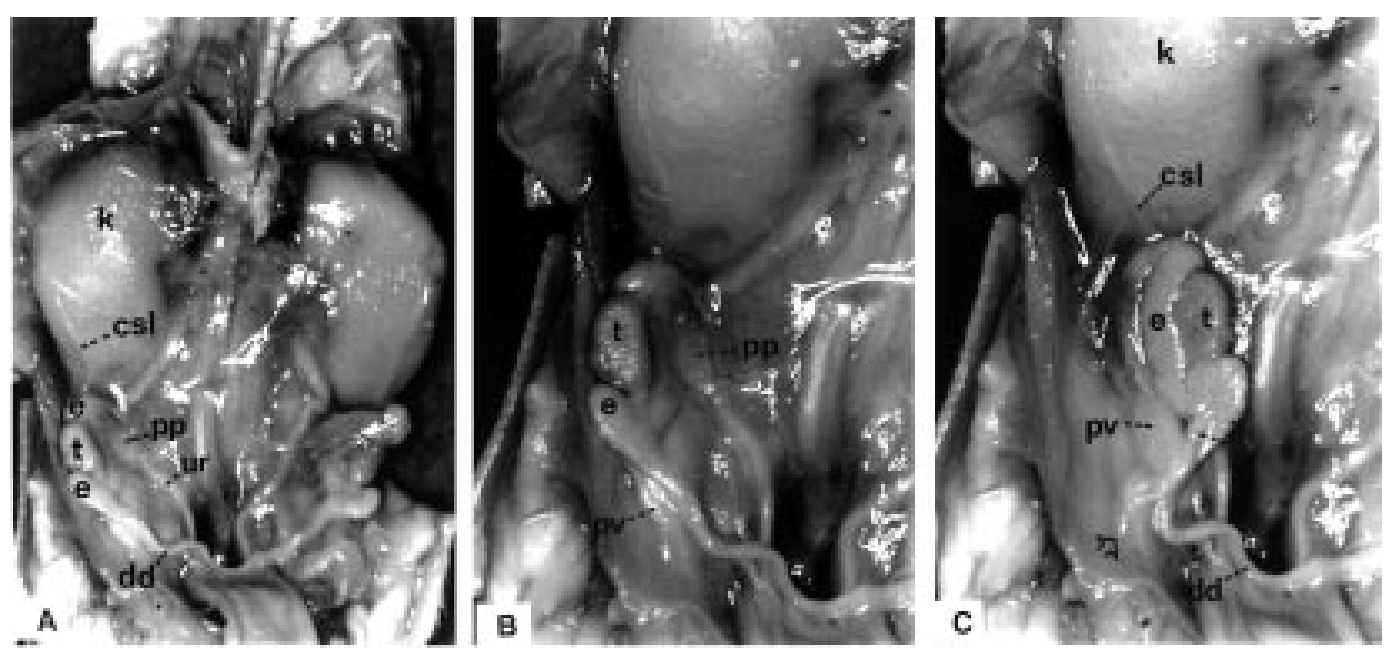

Figure 16. (A-C) Persistence of the cranial suspensory ligament (CSL) in a new-born piglet and its possible role in intra-abdominal retention of the testes in this specimen. In $\mathbf{A}$, an overview in presented of the genitalia in situ with the testis ( $\mathrm{t}$ ) and attached epididymis (e) on both sides close to the caudal pole of the ipsilateral kidney $(\mathrm{k})$. The CSL extends between the cranial pole of the testis/epididymis and the ventral surface of the kidney. The major testicular vasculature ( $\mathrm{pp}=$ plexus pampiniformis) runs from the testis to the body midline. The caudal pole of the epididymis is attached to what appears to be the inverted processus vaginalis (pv). In $\mathbf{B}$, the right testis and associated structures are presented at a higher magnification and as seen in situ. In $\mathbf{C}$, the same organs appear as in $\mathbf{B}$, with the testis and epididymis turned in a medial direction showing the connection (il) between the epididymal cauda and the tip of the inverted processus vaginalis. $\mathrm{DD}=$ deferent duct; $\mathrm{PP}=$ plexus pampiniformis; $\mathrm{UR}=$ ureter; arrowhead indicates base of the inverted processus vaginalis.

the internal genitalia, in particular during the course of pregnancy. The latter puts requirements on suspension of the Müllerian duct derivatives for which there is no precedent in egg-laying submammalian vertebrates.

In male mammals, the CSL appears to play a specific role in facilitating testicular descent. Hormone-dependent developmental events have to take place during the early fetal period to cause inhibition of the outgrowth of these structures. Interference with the proper course of this latter process may be an important, and as yet generally overlooked, factor in the aetiology of testicular maldescent among animals and man.

Neither in male nor in female mammals do the above general rules for male- and female-specific development of the CSL appear without exceptions. In cold-blooded 'primitive mammals' and other testicond species, there is no testis descent and, generally, persistence of the CSL also occurs in males. In various apes and the human species, the female CSL develops into an inconspicuous structure, and this can be easily related to the specific anatomy of the uterus as a single structure in the body midline and the support of the ovaries by structures associated with the pelvis. Bats are among the species in which an unusual specialization of the male CSL has developed which relates to the switch of the position of the testes between an intraand extra-abdominal site.

Hopefully, in the future new insights into the structure and function of the CSL in mammals, including the wide variability between and within species, will contribute to better understanding of normal and aberrant gonadal/ genital anatomy and function among animals and humans.

\section{Acknowledgements}

Thanks are due to Dr F.W.J.Hazebroek (Children's Surgery Department, Erasmus University), J.Heijligers (Pharmacology Department, Erasmus University), W.J.Kersten and Mrs G.Dijkstra (Faculty of Veterinary Sciences, University Utrecht), Professor A.Payne (Anatomy Department, University of Glasgow, UK) and Dr B.Vigier (Université Pierre \& Marie Curie, Paris, France) for their interest and active support during the studies upon which this review has been built. Colleagues in the Endocrinology and Reproduction department (specifically Drs A.O.Brinkmann, W.A.van Capellen, J.A.Grootegoed and A.P.N.Themmen) are cordially thanked for their discussions and critical comments throughout.

\section{References}

Baarends, W.M., van Helmond, M.J.L., Post, M. et al. (1994) A novel member of the transmembrane serine/threonine kinase receptor family is specifically expressed in the gonads and in mesenchymal cells adjacent to the Müllerian duct. Development, 120, 189-197.

Behringer, R.R., Finegold, M.J. and Cate, R.L. (1994) Müllerian-inhibiting substance function during mammalian sexual development. Cell, 79, 415-425.

Brand, T., van der Schoot, P. and Slob, A.K. (1989) Gonadal and genital developmental abnormalities after prenatal exposure of male rats to anti-androgens. In Balthazart, J. (ed.), Proceedings International Conference on Hormones, Brain and Behaviour, Liège, Belgium, pp. $27-28$. 
Cain, M.P., Kramer, S.A., Tindall, D.J. and Husmann, D.A. (1995) Flutamide-induced cryptorchidism in the rat is associated with altered gubernacula morphology. Pediatr. Urol., 46, 553-558.

Ciner, M., van Vorstenbosch, C.J.A.H.V., Dijkstra, G. and van den Hurk, R. (1996) Penile bulb and its relationship with the pelvic urethra in the rat: light and scanning electron microscopical observations. Anat. Rec., 244, 452-469.

Dantschakoff, V. (1941) Der Aufbau des Geschlechts beim höheren Wirbeltier. Fischer, Jena, 466 pp.

de Smet, W.M.A. (1977) The position of the testes in Cetaceans. In Harrison, R.J. (ed.), Functional Anatomy of Marine Mammals, Vol. 3, Academic Press, New York, pp. 361-386.

Dyce, K.M., Sack, W.O. and Wensing, C.J.G. (1996) Textbook of Veterinary Anatomy. Saunders, Philadelphia.

Eales, N.B. (1929) The anatomy of a foetal African elephant (Loxodonta africanus). Trans. R. Soc. Edinb., 56, 203-245.

Eckstein, P. and Zuckerman, S. (1960) The oestrous cycle in the mammalia. In Parkes, A.S. (ed.), Marshall's Physiology of Reproduction, 3rd edn, Vol. 1, part 1, Ch. 4, pp. 226-396, Longmans, London.

England, M.A. (1990) A Colour Atlas of Life before Birth. Wolfe, London.

Frade, F. (1955) Ordre des proboscidiens. In Grassé, J.P. (ed.), Traité de Zoologie, 17, pp. 715-875, Masson, Paris.

Freeman, S. (1990) The evolution of the scrotum: a new hypothesis. $J$. Theor. Biol., 145, 429-445.

Gabella, G. (1976) The costo-uterine muscle of the guinea-pig: a smooth muscle attaching the uterus to the last rib. Anat. Embryol. 150, 35-43.

Gärtner, K. (1969) Hereditärer Kryptorchismus bei Wistarratten. Z. Versuchstierkd., 11, 179-189.

Glickman, S.E., Frank, L.G., Licht, P. et al. (1992) Sexual differentiation of the female spotted hyena. One of Nature's experiments. Ann. N.Y. Acad. Sci., 662, 135-159.

Goffart, M. (1971) Function and Form in the Sloth. Pergamon, Oxford.

Grassé, P.P. (1955) Ordre des insectivores. In Grassé, P.P. (ed.), Traité de Zoologie, 17, pp. 1574-1712, Masson, Paris.

Greene, R.R., Burrill, M.W. and Ivy, A.C. (1938) Experimental intersexuality: the effect of antenatal androgens on sexual development of female rats. Am. J. Anat., 65, 415-469.

Griffiths, M. (1984) Mammals: monotremes. In Lamming, G.E. (ed.), Marshall's Physiology of Reproduction, 4th edn, Vol. 1, Ch. 5. Churchill-Livingstone, Edinburgh, pp. 351-385.

Grinsted, J. and Aagesen, L. (1984) Mesonephric excretory function related to its influence on differentiation of fetal gonads. Anat. Rec., 210, 551-556.

Guglielmone, R. and Vercelli, A. (1991) The costo-uterine muscle of the rat. Anat. Embryol., 184, 337-343.

Habenicht, U.F. and Neumann, F. (1983) Hormonal regulation of testicular descent. Adv. Anat. Embryol. Cell. Biol., 81, 1-54.

Hamilton, W.J., Boyd, J.D. and Mossman, H.W. (1962) Human Embryology. Heffer, Cambridge.

Hinrichsen, K.V. (1990) Humanembryologie. Springer, Berlin.

Husmann, D.A. and McPhaul, M.J. (1991) Time specific androgen blockade with flutamide inhibits testicular descent in the rat. Endocrinology, 129, 1409-1416.

Hutson, J.M. (1986) Testicular feminization: a model for testicular descent in mice and men. J. Pediatr. Surg., 21, 195-198.

Ikadai, H., Ajisawa, C., Taya, K. and Imamichi, T. (1988) Suprainguinal ectopic scrota of TS inbred rats. J. Reprod. Fertil., 84, 701-707.

Jolly, S.E. and Blackshaw, A.W. (1988) Testicular migration, spermatogenesis, temperature regulation and environment of the sheath-tail bat, Taphozous georgianus. J. Reprod. Fertil., 84, 447-455.

Josso, N., Fekete, C., Cachin, O. et al. (1983) Persistence of Müllerian ducts in male pseudohermaphroditism, and its relationship to cryptorchidism. Clin. Endocrinol., 19, 247-258.

Josso, N., Cate, R.L., Picard, J.Y. et al. (1993) Anti-Müllerian hormone: the Jost factor. Recent Prog. Horm. Res., 48, 1-59.

Jost, A. (1953) Problems of fetal endocrinology: the gonadal and hypophyseal hormones. Recent Prog. Horm. Res., 8, 379-418.

Jost, A., Chodkiewicz, M. and Mauléon, P. (1963) Intersexualité du foetus de veau produite par des androgènes. Comparison entre l'hormone foetale responsable du free-martinisme et l'hormone testiculaire adulte. C.R. Acad. Sci., Paris, 256, 274-276.

Jost, A., Vigier, B. and Prépin, J. (1972) Freemartins in cattle: the first steps of sexual organogenesis. J. Reprod. Fertil., 29, 349-379.

Kersten, W., Molenaar, G.J., Emmen, J.M.A. and van der Schoot, P. (1996) Bilateral cryptorchidism in a dog with persistent cranial testis suspensory ligaments and inverted gubernacula: report of a case and its proposed impact for understanding aberrant testis descent. J. Anat., 189, 171-176.

Krutzsch, P.H. (1979) Male reproductive patterns in nonhibernating bats. J. Reprod. Fertil., 56, 333-344.

Lawrence, I.E. and Burden, H.W. (1980) The origin of the extrinsic adrenergic innervation to the rat ovary. Anat. Rec., 196, 51-59.

Lillie, F.R. (1917) The freemartin: a study of the action of sex hormones in the foetal life of cattle. J. Exp. Zool., 23, 371-452.

Lillie, F.R. (1923) Supplementary notes on twins in cattle. Biol. Bull., 44, 47-78.

Lindeque, M. and Skinner, J.D. (1982) Fetal androgens and sexual mimicry in spotted hyenas (Crocuta crocuta). J. Reprod. Fertil., 65, 405-410.

Matthews, L.H. (1939) Reproduction in the spotted hyena Crocuta crocuta (Erxleben). Philos. Trans. R. Soc. Lond., Ser. B., 230, 1-78.

McMahon, D.R., Kramer, S.A. and Husmann, D.A. (1995) Antiandrogen induced cryptorchidism in the pig is associated with failed gubernacular regression and epididymal malformations. J. Urol., 154, $553-557$.

Melton, C.E. and Saldivar, J.T. (1970) Activity of the rat's uterine ligament. Am. J. Physiol., 219, 122-125.

Neumann, F., Von Berswordt-Wallrabe, R., Elger, W. et al. (1970) Aspects of androgen-dependent events as studied by anti-androgens. Recent Prog. Horm. Res., 26, 337-410.

Nickel, R., Schummer, A. and Seiferle, E. (1987) Lehrbuch der Anatomie der Haustiere. Parey, Berlin.

Park, W. and Hutson, J.M. (1991) A new inbred rat strain (TS) with suprainguinal ectopic testes: a model for human cryptorchidism. Pediatr. Surg. Int., 6, 172-175.

Patten, B.M. (1948) Embryology of the Pig, 3rd edn. McGraw-Hill, New York.

Pearson, O.P. (1944) Reproduction in the shrew (Blarina brevicauda Say). Am. J. Anat., 75, 39-93.

Peets, E.A., Henson, M.F. and Neri, R. (1974) On the mechanism of the anti-androgen action of flutamide ( $\alpha$ - $\alpha$ - $\alpha$-trifluoro-2-methyl4-nitro-m-propionotoluidide) in the rat. Endocrinology, 94, 532-540.

Polani, P.E. (1970) Hormonal and clinical aspects of hermaphroditism and the testicular feminizing syndrome in man. Philos. Trans. R. Soc. Lond., Ser. B., 259, 187-204.

Raynaud, A. (1969) Les organes génitaux des Mammifères. In Grassé, P. (ed.), Traité de Zoologie, 16, pp. 148-636, Masson, Paris.

Roche, P.J., Parkington, H.C. and Gibson, W.R. (1985) Pregnancy and parturition in rats after sympathetic denervation of the ovary, oviduct and utero-tubal junction. J. Reprod. Fertil., 75, 653-661.

Romanes, G.J. (1981) Cunningham's Textbook of Anatomy, 4th edn. Oxford University Press, Oxford.

Romer, A.S. (1949) The Vertebrate Body. Saunders, Philadelphia.

Rouvière, H. (1932) Anatomie Humaine Descriptive et Topografique. Masson, Paris.

Schulte, T.L. (1937) The genito-urinary system of the elephas indicus male. Am. J. Anat., 61, 131-157.

Shono, T., Ramm-Anderson, S., Goh, D.W. and Hutson, J.M. (1995) Transabdominal descent is really ovarian ascent. J. Urol., 152, 781-784.

Slijper, E.J. (1966) Functional morphology of the reproductive system in cetacea. In Norris, K.S. (ed.), Whales, Dolphins and Porpoises. University of California Press, Berkeley, pp. 277-318.

Södersten, P., Damassa, D.A., Smith, E.R. and Davidson, J.M. (1975) Effects of a non-steroidal antiandrogen on sexual behavior and pituitary-gonadal function in the male rat. Endocrinology, 97, 1468-1475.

Sonneland, S.G. (1925) Undescended testicle. Surg. Gynecol. Obstet., 40, 535-545. 
Spencer, J.R., Torrado, T., Sanchez, R.S. et al. (1991) Effects of flutamide and finasteride on rat testicular descent. Endocrinology, 129, 741-748.

Spencer Barthold, J., Mahler, H.R. and Newton, B.W. (1994) Lack of feminization of the cremaster nucleus in cryptorchid androgen insensitive rats. J. Urol., 152, 2280-2286.

Stallings, M.W., Rose, A.H., Auman, G.L. and Cunningham, R.D. (1976) Persistent Müllerian structures in a male neonate. Pediatrics, 57, 568-569.

Stanley, A.J., Gumbeck, L.G. and Allison, J.E. (1973) Male pseudohermaphroditism in the laboratory Norway rat. Recent Prog. Horm. Res., 29, 43-64.

van der Schoot, P. (1992a) Androgens in relation to prenatal development and postnatal inversion of the gubernacula in rats. J. Reprod. Fertil., 95, 145-158.

van der Schoot, P. (1992b) Disturbed testicular descent in the rat after prenatal exposure to the antiandrogen flutamide. J. Reprod. Fertil. 96, 483-496.

van der Schoot, P. (1993a) Doubts about the 'first phase of testis descent' in the rat as a valid concept. Anat. Embryol., 187, 203-208.

van der Schoot, P. (1993b) The name cranial ovarian suspensory ligaments in mammalian anatomy should be used only to indicate the structures derived from the foetal cranial mesonephric and gonadal ligaments. Anat. Rec., 237, 434-438.

van der Schoot, P. (1995) Studies on the fetal development of the gubernaculum in Cetacea. Anat. Rec., 243, 449-460.

van der Schoot, P. (1996a) Foetal genital development in Hyrax capensis, a species with primary testicondia: proposal for the evolution of Hunter's gubernaculum. Anat. Rec., 244, 386-401.

van der Schoot, P. (1996b) Human (and some other primates') uterine teres ligament represents a mammalian developmental novelty. Anat. Rec., 244, 402-415.

van der Schoot, P. (1996c) Towards a rational terminology in the study of the gubernaculum testis: arguments in support of the notion that the cremasteric sac should be considered the gubernaculum in postnata rats and other mammals. J. Anat., 189, 97-108.

van der Schoot, P. and Elger, W. (1992) Androgen-induced prevention of the outgrowth of cranial gonadal suspensory ligaments in fetal rats. $J$. Androl., 13, 534-542.

van der Schoot, P. and Elger, W. (1993) Perinatal development of the gubernacular cones in rats and rabbits: effect of exposure to anti-androgens. Anat. Rec., 236, 399-407.

van der Schoot, P., Vigier, B., Prépin, J. et al. (1995) The development of the gubernaculum and processus vaginalis in freemartinism: further evidence in support of a specific testis hormone governing male-specific gubernacular development. Anat. Rec., 241, 211-224.

Viguier-Martinez, M.C., Hochereau de Reviers, M.T., Barenton, B. and Perreau, C. (1983) Effect of a non-steroidal antiandrogen, flutamide, on the hypothalamo-pituitary axis, genital tract and testis in growing male rats: endocrinological and histological data. Acta Endocrinol., 102, 299-306.

Weber, M. (1898) Studien über Säugethiere. Fischer, Jena.

Weber, M. (1927/28) Die Säugetiere (2 volumes). Fischer, Jena.

Wilson, J.D., Griffin, J.E., George, F.W. and Leshin, M. (1981) The role of gonadal steroids in sexual differentiation. Recent Prog. Horm. Res., 37, 1-39.

Wilson, J.D., George, F.W. and Renfree, M.B. (1995) The endocrine role in mammalian sexual differentiation. Recent Prog. Horm. Res., 50, 349-364.

Wylie, S.N., Roche, P.J. and Gibson, W.R. (1985) Ovulation after sympathetic denervation of the rat ovary produced by freezing its nerve supply. J. Reprod. Fertil., 75, 369-373.

Yalcinkaya, T.M., Siiteri, P.K., Vigne, J.L. et al. (1993) A mechanism for virilization of female spotted hyenas in utero. Science, 260, 1929-1931.

Received on May 7, 1996; accepted on September 23, 1996 